\title{
Terrestrial responses of low-latitude Asia to the Eocene-Oligocene climate transition revealed by integrated chronostratigraphy
}

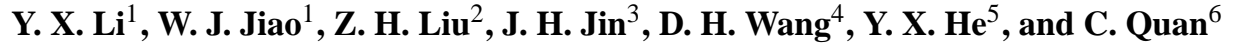 \\ ${ }^{1}$ State Key Laboratory for Mineral Deposits Research, Key Laboratory of Surficial Geochemistry, Ministry of Education, \\ School of Earth Sciences and Engineering, 210046 Nanjing, China \\ ${ }^{2}$ Department of Earth Sciences, The University of Hong Kong, Hong Kong, China \\ ${ }^{3}$ State Key Laboratory of Biocontrol and Guangdong Provincial Key Laboratory of Plant Resources, School of Life Sciences, \\ Sun Yat-sen University, 510275 Guangzhou, China \\ ${ }^{4}$ College of Earth Sciences, Jilin University, 130061 Changchun, China \\ ${ }^{5}$ Department of Earth Sciences, Zhejiang University, Hangzhou, China \\ ${ }^{6}$ Research Center of Paleontology and Stratigraphy, Jilin University, 130026 Changchun, China
}

Correspondence to: Y. X. Li (yxli@nju.edu.cn) and C. Quan (quan@jlu.edu.cn)

Received: 1 May 2015 - Published in Clim. Past Discuss.: 8 July 2015

Revised: 10 January 2016 - Accepted: 14 January 2016 - Published: 11 February 2016

\begin{abstract}
The Paleogene sedimentary records from southern China hold important clues to the impacts of the Cenozoic climate changes on low latitudes. However, although there are extensive Paleogene terrestrial archives and some contain abundant fossils in this region, few are accurately dated or have a temporal resolution adequate to decipher climate changes. Here, we present a detailed stratigraphic and paleomagnetic study of a fossiliferous late Paleogene succession in the Maoming Basin, Guangdong Province. The succession consists of oil shale of the Youganwo Formation (Fm) in the lower part and the overlying sandstone-dominated Huangniuling Fm in the upper part. Fossil records indicate that the age of the succession possibly spans the late Eocene to the Oligocene. Both the Youganwo Fm and the overlying Huangniuling Fm exhibit striking sedimentary rhythms, and spectral analysis of the depth series of magnetic susceptibility of the Youganwo Fm reveals dominant sedimentary cycles at orbital frequency bands. The transition from the Youganwo oil shale to the overlying Huangniuling sandstones is conformable and represents a major depositional environmental change from a lacustrine to a deltaic environment. Integrating the magnetostratigraphic, lithologic, and fossil data allows establishing a substantially refined chronostratigraphic framework that places the major depositional environmental
\end{abstract}

change at $33.88 \mathrm{Ma}$, coinciding with the Eocene-Oligocene climate transition (EOT) at $\sim 33.7$ to $\sim 33.9 \mathrm{Ma}$. We suggest that the transition from a lacustrine to deltaic environment in the Maoming Basin represents terrestrial responses to the EOT and indicates prevailing drying conditions in lowlatitude regions during the global cooling at EOT.

\section{Introduction}

The late Paleogene witnessed one of the most prominent climatic changes in the Cenozoic, a transition from greenhouse to icehouse world. The transition climaxed at the EoceneOligocene boundary when marine sediments registered a large, widespread, and rapid cooling in oceans (e.g., Zachos et al., 2001; Liu et al., 2009; Bohaty et al., 2012), which was accompanied by a sudden deepening of the carbonate compensation depth (CCD) by $\sim 1.2 \mathrm{~km}$ (Pälike et al., 2012) in oceans and a calamity in the marine community that gave rise to the largest marine mass extinction since the end of Cretaceous (e.g., Prothero, 1994; Pearson et al., 2008; Cotton and Pearson, 2011). On land, this transition is expressed as rapid ice sheet growth over Antarctica (e.g., DeConto and Pollard, 2003; Coxall et al., 2005; Goldner et al., 2014) and largescale cooling (e.g., Zanazzi et al., 2007; Dupont-Nivet et al., 
2007; Hren et al., 2013). While the transition is widely recognized in the marine realm (Zachos et al., 2001; Jovane et al., 2006; Liu et al., 2009; Pälike et al., 2012; Westerhold et al., 2014) and is increasingly well-defined in terrestrial records from the Atlantic region (e.g., Zanazzi et al., 2007; Hren et al., 2013), its impacts on the Asian environment remain poorly understood. This is largely because the concomitant tectonism, i.e., the Tibetan Plateau uplift, and the development of monsoonal climate may also have a strong influence on the Asian environment (e.g., Dupont-Nivet et al., 2007; Quan et al., 2012, 2014; Wang et al., 2013; Licht et al., 2014, 2015; Shukla et al., 2014).

There are numerous basins in southern China that host conspicuous Cenozoic sedimentary archives documenting the Cenozoic climate changes in the region. The late Paleogene sedimentary records from this region are of particular interest because they hold clues to the dramatic shift of climates in low-latitude Asia (Quan et al. 2012; Wang et al., 2013; Licht et al., 2014, 2015), where the influence of the Tibetan Plateau uplift should be minimal in comparison to the Asian interior. However, although abundant Paleogene sedimentary successions were developed here (e.g., Tong et al., 2005, 2013), their age controls are generally poor. Despite the fact that some successions contain vertebrate and/or plant fossils (e.g., Tong et al., 2005, 2013), the indicative age ranges of these fossils are often too broad to date climate changes with satisfactory accuracy and precision.

In this paper, we present a detailed stratigraphic and paleomagnetic study on the fossiliferous Eocene to Oligocene succession in the Maoming Basin of Guangdong Province, southern China, to construct a new chronostratigraphic framework that is based on an integrated litho-, bio-, magneto-, and cyclostratigraphy. The new chronology not only greatly reduces the uncertainty but also significantly refines the available fossil-based timescale of the succession. In particular, the substantially refined chronology permits establishing the link between the dramatic environmental change in the basin and the global Eocene-Oligocene climatic transition and thus provides a critical chronological basis for further detailed examination of climate changes in this region.

\section{Geologic setting}

The Maoming Basin is an intramontane basin situated in the southwestern part of Guangdong Province, southern China (Fig. 1). From the bottom to the top, the Cenozoic succession of the basin consists of the Shangdong Formation (Fm), Youganwo Fm, Huangniuling Fm, Shangcun Fm, Laohuling Fm, and Gaopengling Fm (BGMRGP, 1988, 1996). Among these units, the Eocene to Oligocene strata are found in the Youganwo Fm and the Huangniuling Fm (Fig. 2).

The Youganwo Fm is characterized by the occurrence of siltstones and shales containing coal seams in the lower part and the predominant occurrence of oil shales in the upper
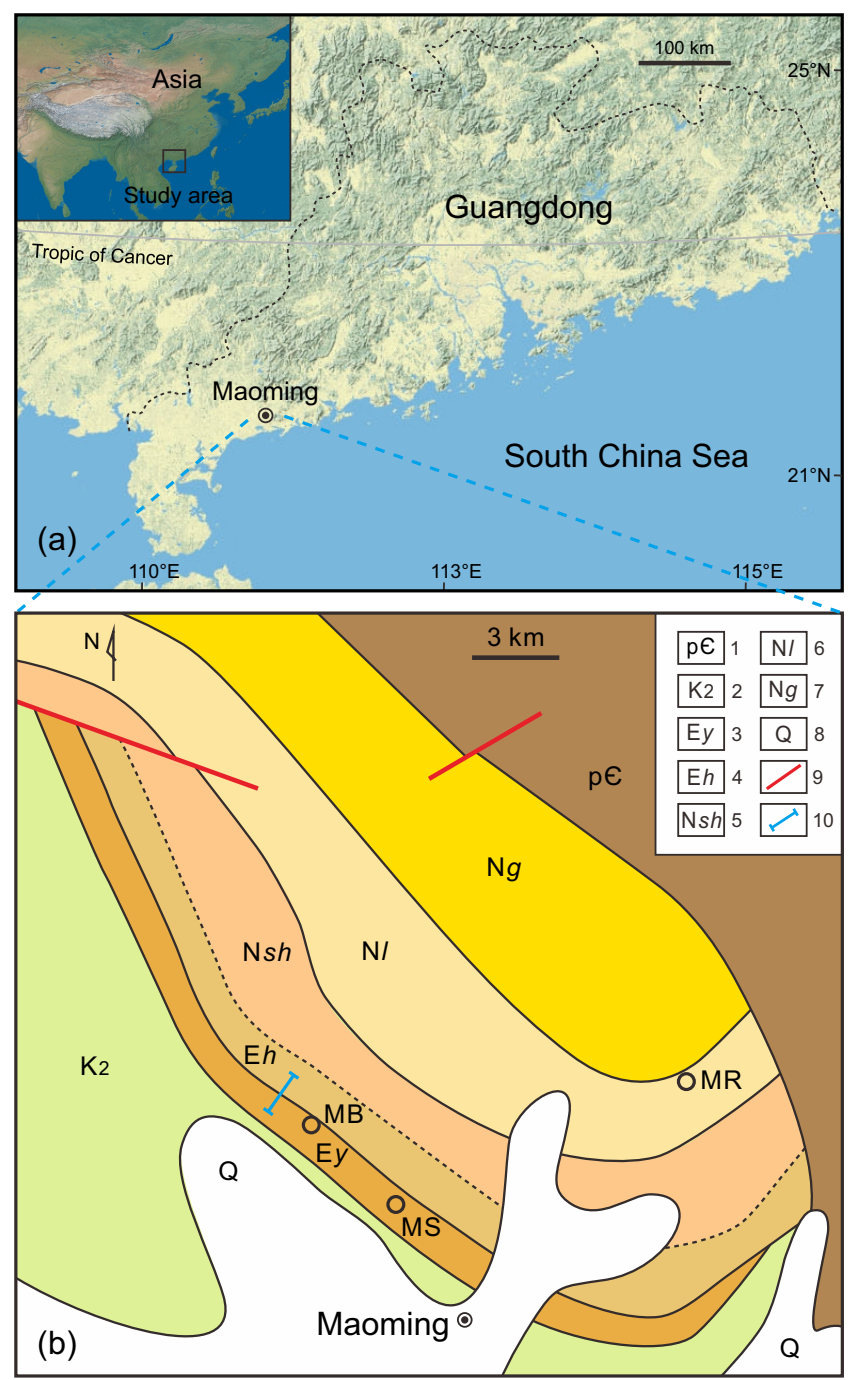

Figure 1. Location and regional geology of the study area. Panel (a): map showing the location of the Maoming Basin, Guangdong Province, southern China. Panel (b): simplified geological map of the Maoming Basin: 1. Precambrian; 2. Upper Cretaceous; 3. Youganwo Fm.; 4. Huangniuling Fm.; 5. Shangcun Fm.; 6. Laohuling Fm.; 7. Gaopengling Fm.; 8. Quaternary; 9. fault; 10. Jintang section investigated. MR, MB, and MS mark the sites where samples were collected for a magnetostratigraphic study by Wang et al. (1994). See text for details.

part (Fig. 2). The Youganwo Fm contains abundant vertebrate and plant fossils including the turtle species Anosteira maomingensis, Isometremys lacuna, and Adocus inexpectatus (Chow and Liu, 1955; Chow and Yeh, 1962; Claude et al., 2012; Danilov et al., 2013), the crocodile species Tomistoma petrolica and Alligatoridae (Yeh, 1958; Li, 1975; Skutschas et al., 2014), the fish species Cyprinus maomingensis (Liu, 1957), the mammalian species Lunania cf. L. youngi (Wang et al., 2007), and the wood species Bischofia maomingensis and Myrtineoxylon maomingensis (Feng et al., 2012; Os- 
(a)

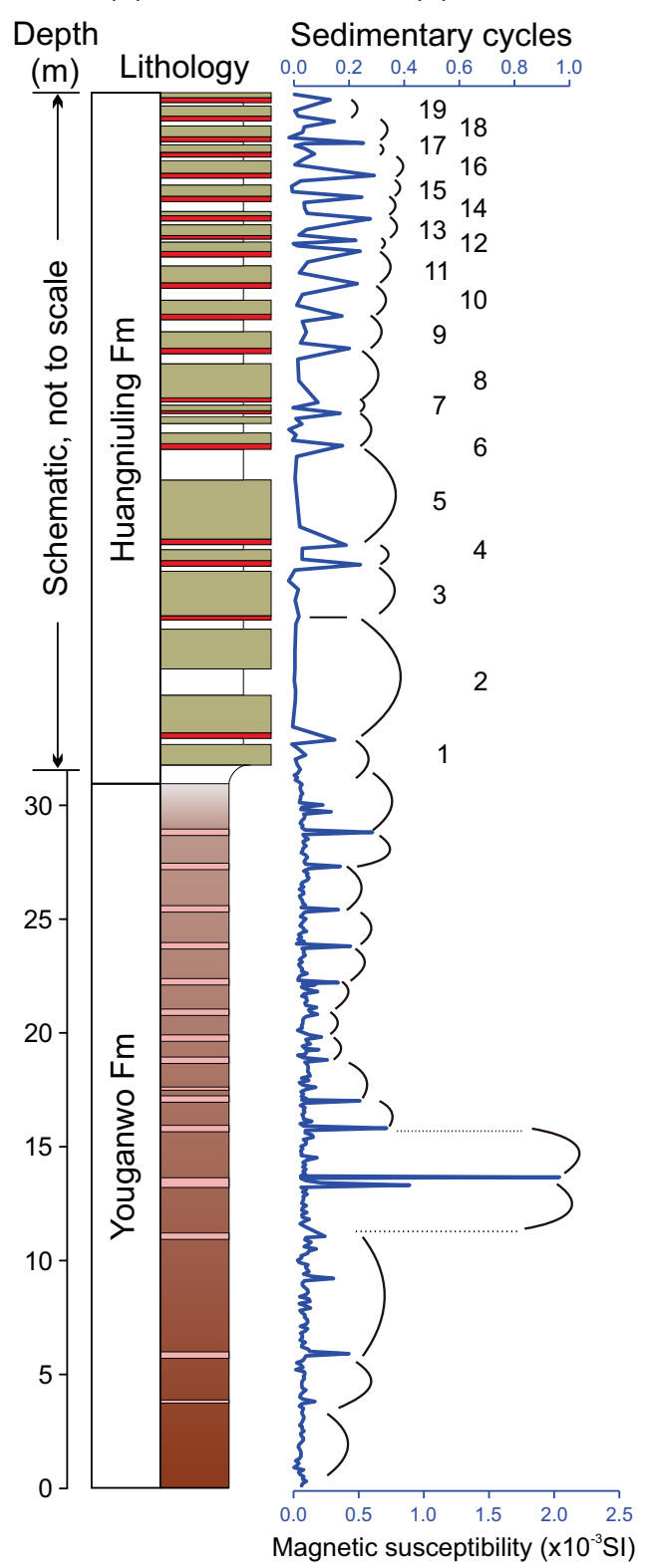

(b)

Sedimentary cycles $\begin{array}{llllll}0 & 0.2 & 0.4 & 0.6 & 0.8 & 1.0\end{array}$ (c) Huangniuling Fm
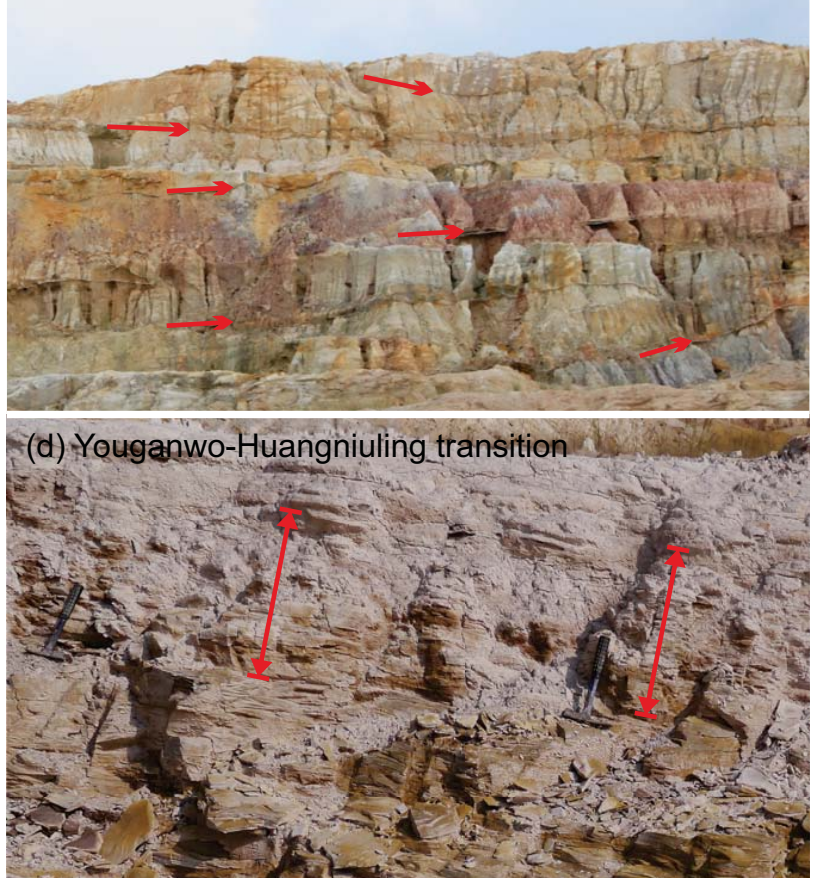

(e) Youganwo Fm

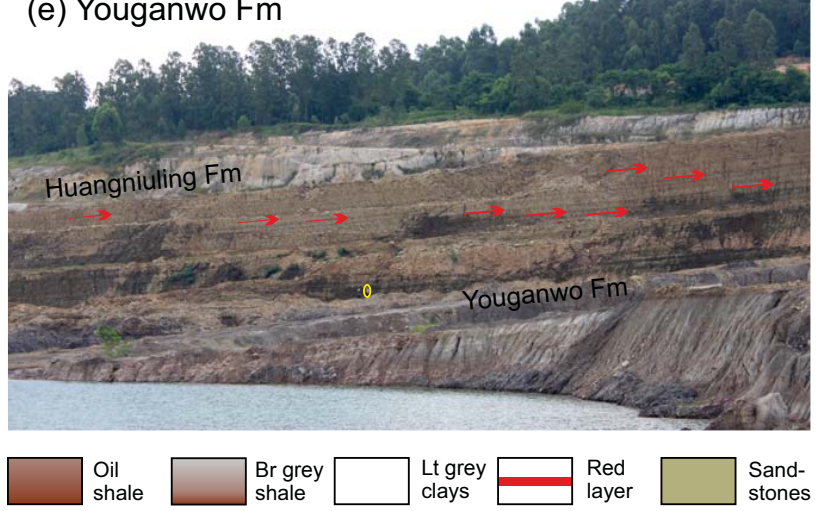

Figure 2. Stratigraphy of the investigated section exposed in the now abandoned open mine pit in the Maoming Basin. Lithostratigraphic column (a) shows that the investigated section contains the Youganwo Fm and the overlying Huangniuling Fm. The stratigraphic column of the upper part of the Huangniuling Fm schematically shows the overall rhythmic sedimentary feature that is characterized by the repeated occurrence of a sedimentary package that is composed of a thin bed (shown in red lines) of red sandstone at the base, massive grey sandstone in the middle, and a light grey mudstone bed at the top. The Youganwo Fm also exhibits sedimentary rhythms that are characterized by repeated occurrence of the beds with distinct reddish color (shown in pinkish lines) visible from a distance. Sedimentary cycles (b) are reflected by magnetic susceptibility data. The distinct reddish beds in the Youganwo Fm and the thin red sandstone layers in the Huangniuling Fm generally correspond to the magnetic susceptibility peaks. The distinct thin red sandstone layer of a sedimentary package in the Huangniuling Fm is numbered and a total of 19 sedimentary packages are identified. Note the different scales of the magnetic susceptibility of the Youganwo Fm (the lower part) and the Huangniuling Fm (the upper part). Field photographs (c-e) show the major sedimentary features of the two formations and the contact between them. In (c), the red arrows indicate the red, thin marker bed of sandstone in the Huangniuling Fm. In (d), the arrow marks the contact between the two formations, displaying a continuous, gradual transition from brown grey mudstones in the uppermost section of the Youganwo Fm to pale grey mudstones at the base of the Huangniuling Fm. In (e), the yellow ellipse at the lower-middle part of the picture marks a person $(\sim 1.6 \mathrm{~m})$ for scale; red arrows point to several distinctive reddish layers that form the sedimentary rhythms in the Youganwo Fm; "br grey": brown grey; "It grey": light grey. 
kolski et al., 2013). The age of the formation is controversial, with suggested dates varying from the Eocene to the Oligocene (e.g., Liu, 1957; Yeh, 1958; Yu and Wu, 1983). A comprehensive review of the fossil records suggests that the Youganwo Fm was most likely deposited in the late Eocene (Jin, 2008). The late Eocene age is interpreted to include both the Priabonian Stage and the Bartonian Stage of the Eocene based on recent advances in understanding fossil mammals of Lunania. Although the systematic position of the genus Lunania is still not fully understood, increasing evidence appears to constrain its age to the Bartonian to Priabonian Stage of the Eocene. To date, two species in total have been reported: Lunania zhoui from the Yuanqu Basin in central China (Huang, 2002) and Lunania youngi from Yunnan (Chow, 1957; Zong et al., 1996) and Maoming (Wang et al., 2007) in southern China. The geological age of $L u$ nania zhoui is regarded to be no earlier than the Bartonian and no later than the Priabonian Stage (Tong et al., 2005). For the Lunania youngi from Yunnan, it has been considered to date to the Bartonian to Priabonian stages ( $\mathrm{Li}$ and Ting, 1983; Russell and Zhai, 1987; Wang, 1992; Qiu and Wang, 2007), to the Bartonian (Tong et al., 1995), to the early late Eocene (Huang and Qi, 1982), or to the end of the Eocene (Tong et al., 2005; Wang, 1997). Therefore, the late Eocene age of the mammal fossil in the Maoming Basin should be understood as including both the Priabonian Stage and the Bartonian Stage of the Eocene.

The overlying Huangniuling Fm consists mainly of sandstones and siltstones (Fig. 2). The lower part of the Huangniuling Fm is dominated by massive, pebbly coarse sandstones interbedded with thinly bedded, grey, silty mudstones. This formation contains plenty of plant macrofossils such as fruits and leaves (e.g., Feng et al., 2013). The age of the Huangniuling Fm has been ascribed to the late Eocene to Oligocene or even to the Miocene (Yu and Wu, 1983; Wang et al., 1994; Guo, 2006; Aleksandrova et al., 2012).

The areal extent of these two formations and other Cenozoic architectural units in the Maoming Basin was mapped by Guo (2006), who compiled stratigraphic data from drill cores and outcrops. Sedimentary facies analyses of these sedimentary units indicate that the alluvial fan and fan delta were initially developed in the northeastern part of the basin, which gradually gave rise to a lacustrine environment that expanded to the whole basin and alternated with a deltaic environment as the lake area grew and decreased again (Guo, 2006). Accordingly, successions that were accumulated in the lacustrine and deltaic environments often exhibit various subfacies and microfacies. For instance, subfacies and microfacies analysis indicates that the lower part of the Youganwo Fm was initially formed in a littoral zone or shallow-lake environment that was replaced by a prodelta environment and subsequently by a shallow-lake environment (Guo, 2006). The oil shale that dominated the upper part of the Youganwo Fm was deposited mainly in semi-deep- or deep-lake environments that gave rise to a shallow-lake environment in the uppermost section of the Youganwo Fm. The Huangniuling Fm was deposited predominately in deltaic environments that vary from prodelta and delta front to delta plain environments (Guo, 2006). The uppermost part of the Huangniuling Fm, which mainly consists of muddy siltstone and mudstones, was deposited in a prodelta environment that transitioned to a shallow-lake environment where the younger Shangcun Fm was deposited.

A magnetostratigraphic study has previously been conducted in the Maoming Basin (Wang et al., 1994). The paleomagnetic data were collected from three different sites - drill cores MR and MB as well as an outcrop section MS (Fig. 1b) - and stratigraphic data from these three sites were compiled to obtain a composite stratigraphy that comprises the upper part of the Youganwo Fm, Huangniuling Fm, Shangcun Fm, and Laohuling Fm. The age of the composite stratigraphy was interpreted to span chron $18 \mathrm{n}$ to chron $12 \mathrm{n}$ (Wang et al., 1994). However, the magnetostratigraphy of Wang et al. (1994) can only be regarded as preliminary by modern standards because of the following reasons. The mean sampling spacing is large $(\sim 2.6 \mathrm{~m})$. In addition, changes in sedimentation rates as indirectly reflected by the lithology were not taken into account. Furthermore, although samples of the Huangniuling Fm, Shangcun Fm, and Laohuling Fm were collected from the same core, i.e., the $874 \mathrm{~m}$ long MR core, samples of the Youganwo Fm were collected from both the MB core (15 samples) and the MS section (17 samples). The $\mathrm{MB}$ core is $567 \mathrm{~m}$ long, penetrates the Cenozoic strata, and reaches the Cretaceous rocks. No details were available as to how these 32 samples from two different sites were integrated to make a composite stratigraphy for the Youganwo Fm, particularly given that the MB core is relatively condensed and its base reaches the Cretaceous rocks. In particular, concerning the stratigraphic interval equivalent to that of this study, i.e., the upper Youganwo Fm and the lower Huangniuling Fm, the sampling spacing was on average about $6.0 \mathrm{~m}$ (Figs. 2 and 5 of Wang et al., 1994), which is too large by modern standards.

\section{Methods}

The study section is well exposed in the cliffs of the now abandoned open mine pit $\left(21^{\circ} 42.3^{\prime} \mathrm{N}, 110^{\circ} 53.9^{\prime} \mathrm{E}\right)$, located to the northwest of Maoming City (Fig. 1). The exposed section comprises the upper part of the Youganwo Fm and the overlying Huangniuling Fm. In this study, the upper $31.5 \mathrm{~m}$ of the Youganwo Fm and the basal $30 \mathrm{~m}$ of the Huangniuling Fm were measured. Major lithological changes in the upper part of the Huangniuling Fm are noted. To detect subtle changes in the lithology of the exposed Youganwo Fm, magnetic susceptibility was measured with a handheld susceptibility meter, SM30, typically at every 10 to $20 \mathrm{~cm}$. Spectral analysis of the depth magnetic susceptibility data series was performed using the technique of Muller and MacDon- 
ald (2000) to detect the dominant sedimentary cycles. The raw magnetic susceptibility data series was first linearly interpolated, detrended, and subjected to a band-pass filter of $1 / 1000-1 / 10$ cycles $\mathrm{cm}^{-1}$. The prepared magnetic susceptibility data series in the depth domain was then used to perform fast Fourier transforms (FFTs), yielding a series of spectral peaks. To identify the statistically significant spectral peaks, noise estimation using the Monte Carlo approach (Mader et al., 2004) was carried out. This approach involves combining FFTs on 1000 randomly generated data sets to produce a $95 \%$ confidence curve. Spectral peaks rising above the confidence curve are considered statistically significant. To further test whether the dominant sedimentary cycles, as represented by the statistically significant spectral peaks, are within orbital frequency bands, cycle wavelength ratios (CWRs) of the dominant sedimentary cycles are examined and compared with the periodicity ratios of orbital cycles following Fischer (1991).

Oriented paleomagnetic samples were collected from the exposed Youganwo Fm and the lower part of the overlying Huangniuling Fm at a depositional center of the basin where the gradual transition between the two formations occurs (see Sect. 4.1). For oil shales in the Youganwo Fm, samples were usually collected every $\sim 30$ to $40 \mathrm{~cm}$ and, where possible, two core samples were taken from a stratigraphic level. For the Huangniuling Fm, samples were mainly collected from the interbedded thin, grey mudstones. A gasoline-powered portable rock drill was used to collect samples and a Pomery orientation device was used to orient the samples. Oriented block samples were taken from outcrops where drilling is not possible. A total of 109 core samples and 66 block samples from 122 stratigraphic levels were collected from this section.

In the laboratory, the samples were trimmed to standard cylindrical paleomagnetic specimens or cut into $2 \mathrm{~cm}$ cubes $\left(8 \mathrm{~cm}^{3}\right)$. Anisotropy of magnetic susceptibility (AMS) of all specimens was measured with a KLY-3 Kappabridge. The specimens were then subjected to progressive thermal or AF (alternating field) demagnetization. The AF demagnetization was performed with a Molspin demagnetizer and the thermal demagnetization was conducted with an ASC TD48 thermal demagnetizer. The remanence of specimens was measured with a three-axis, $2 \mathrm{G}$ Enterprise Inc. 755 rock magnetometer. To constrain the magnetic mineralogy, isothermal remanent magnetization (IRM) acquisition was conducted with an ASC impulse magnetizer (IM-30) for selected samples. In the IRM acquisition experiments, each sample was magnetized in a forward field that progressively increases from $20 \mathrm{~m} T$ to $1.2 T$. The sample was then progressively demagnetized in a backward field to estimate the coercivity of magnetic minerals. Between each magnetization (or demagnetization) treatment, the remanence of the sample was measured with an AGICO JR6A magnetometer. In addition, selected samples were subjected to a Lowrie test (Lowrie, 1990) to further constrain the magnetic mineral- ogy. In the Lowrie test, the samples were first magnetized sequentially along their $z, y$, and $x$ axes with fields of 1.2, 0.6, and $0.125 T$, respectively, and the composite IRM was then thermally demagnetized up to $640^{\circ} \mathrm{C}$. To further aid magnetic mineralogy determination, thermal changes in magnetic susceptibility of representative samples from the Youganwo Fm and the Huangniuling Fm were measured with a multifunction Kappabridge (MFK) equipped with CS-4 furnace. The magnetic susceptibility of the samples was measured while the samples were heated and cooled between room temperature and $700{ }^{\circ} \mathrm{C}$ in an argon environment. In addition, zero-field-cooled (ZFC) and field-cooled (FC) lowtemperature measurements were conducted with a Quantum Design Magnetic Property Measurement System (MPMS) at the Paleomagnetism and Geochronology Laboratory, Chinese Academy of Science. All the demagnetization experiments and remanence measurements were conducted in a magnetically shielded room (residual field $<300 \mathrm{nT}$ ) in the Paleomagnetism Laboratory of Nanjing University, China.

The demagnetization data were analyzed using the principal component analysis technique (Kirschvink, 1980). The demagnetization data are presented graphically by vector end point diagrams (Zijderveld, 1967). Software packages PuffinPlot (Lurcock and Wilson, 2012) and PMGSC (by Randy Enkin) were used for paleomagnetic data analysis. The defined polarity zones, together with constraints from the paleontologic and lithologic data, are compared with the geomagnetic polarity timescale (GPTS) of Ogg (2012) to establish a chronological framework for the investigated section.

\section{Results}

\subsection{Sedimentary rhythms}

The lithostratigraphy of the investigated section is summarized in Fig. 2. From a distance, the lithology difference between the Youganwo Fm in the lower part and the Huangniuling Fm in the upper part of the section is indicated by the distinct color contrast (Fig. 2c-e). The overall light brownish color in the lower part characterizes the exposed Youganwo $\mathrm{Fm}$, while the overall pale grey to light yellowish color in the upper part characterizes the overlying Huangniuling Fm (Fig. 2e). The investigated Youganwo Fm consists predominately of brown to dark brown oil shales, with faint thin laminations. Brown grey to grey mudstone occurs in the uppermost section of the Youganwo Fm. The overlying Huangniuling Fm contains dominantly massive sandstone and siltstone beds that are interbedded with pale grey to grey thin mudstone beds.

One of the most striking features of the outcrop is the occurrence of sedimentary rhythms, which are impressively expressed as the repeated occurrence of beds with a distinct reddish color in both the Youganwo Fm and the Huangniuling Fm (Fig. 2c, e). In the Youganwo Fm, there are more than 


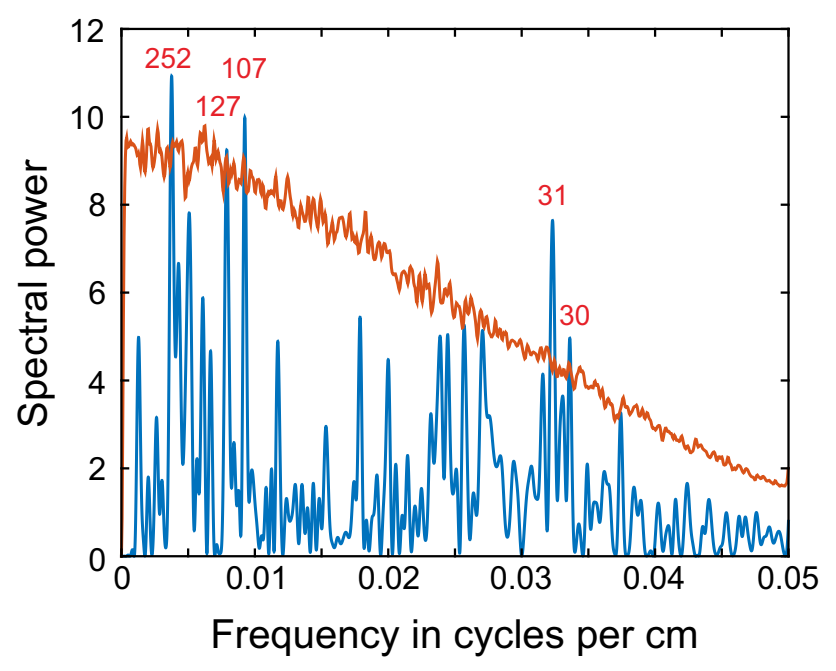

Figure 3. Spectral analysis of the depth series of magnetic susceptibility data of the Youganwo oil shale. The analysis reveals dominant sedimentary cycles with cycle wavelength ratios similar to periodicity ratios of orbital cycles, suggesting that these sedimentary cycles probably represent orbital cycles. The red curve represents the noise level above which the spectral peaks are considered statistically significant. The numbers above the spectral peaks indicate cycle wavelengths (in centimeters) of the sedimentary cycles. See text for details.

a dozen beds displaying a distinct reddish color (Fig. 2a). The sedimentary rhythm is particularly well expressed between $\sim 11$ and $30 \mathrm{~m}$, where the average spacing between two neighboring reddish beds is about 1.0 to $1.5 \mathrm{~m}$ (Fig. 2a). Inspection of the beds with reddish color at the outcrop found that the reddish coloration only occurs at the surface and represents weathering banding of the beds because the fresh exposure of these beds does not show reddish color. Despite the fact that the reddish color represents recent weathering, not the depositional signature, weathering enhanced the expression of changes in lithology and made the subtle lithological changes more distinctly and strikingly visible on the outcrop. Because the reddish layers correspond to higher magnetic susceptibility values and less reddish levels display relatively lower magnetic susceptibility values, magnetic susceptibility data can facilitate the characterization of sedimentary cycles in the Youganwo Fm. Indeed, our high-resolution magnetic susceptibility data also exhibit meter-scale cyclicity (Fig. 2b). Spectral analysis of the magnetic susceptibility data reveals dominant sedimentary cycles with a cycle wavelength of $\sim 252,127$ to 107, and $\sim 30 \mathrm{~cm}$ (Fig. 3). The 127 to $107 \mathrm{~cm}$ cycle and the $\sim 30 \mathrm{~cm}$ cycle have a cycle wavelength ratio of $3.6: 1$ to $4.2: 1$. The $\sim 252 \mathrm{~cm}$ cycle and the 127 to $107 \mathrm{~cm}$ cycle have a cycle wavelength ratio ranging from $1.98: 1$ to $2.35: 1$.

The point of contact between the Youganwo Fm and the overlying Huangniuling Fm is abrupt at many locations around the edge of the open mine pit where the siltstone- and sandstone-dominated Huangniuling Fm sits directly atop of brown grey to dark grey mudstones of the upper part of the Youganwo Fm. However, when the contact is traced toward the center of the basin, the interface between the two formations is represented by a $\sim 50 \mathrm{~cm}$ thick layer that displays a continuous, gradual change from brown grey mudstones in the uppermost section of Youganwo Fm to pale grey mudstones at the base of the Huangniuling Fm (Fig. 2d). Above the pale grey mudstone are siltstones and sandstones, exhibiting a coarsening upward trend in grain size. Further upsection, the siltstones and sandstones are interbedded with thin layers of pale grey mudstones in the lower part of the Huangniuling Fm.

In the Huangniuling Fm, sedimentary rhythms are indicated by the repeated occurrence of distinct red layers. The red layer occurs at the base of the pale grey massive coarse sandstone and is typically a few centimeters thick. The basal red sandstones are more resistant to weathering than the rest of the massive sandstones and commonly stick out of the surface of the outcrop, making the distinct red layers readily recognizable from a distance (Fig. 2c). The thickness of the massive sandstone varies largely from decimeters to meters, occasionally up to dekameters. Typically, there is a relatively thinner mudstone bed above massive sandstones (Fig. 2c). A red layer, massive sandstones, and a thin mudstone bed appear to form a parasequence that occurs repeatedly across the Huangniuling Fm (Fig. 2a, b, c). In the lower part of the Huangniuling Fm, the sandstone and mudstone beds in the parasequence are nearly flat and extend laterally with uniform thickness for hundreds of meters, and there is a finingupward trend within a parasequence. In the upper part of the Huangniuling Fm, lens-shaped channelized sandstones are occasionally observed. Using the distinct red layer in a parasequence as a marker bed, we have counted 19 parasequences in the exposed Huangniuling Fm (Fig. 2a, b).

\subsection{Rock magnetic data}

\subsubsection{Anisotropy of magnetic susceptibility (AMS)}

The AMS data of the Youganwo samples show predominantly oblate fabrics with the minimum axes perpendicular to the bedding and the maximum and intermediate axes parallel or subparallel to the bedding (Fig. 4a, b). The degree of anisotropy ( $\mathrm{Pj}$ ) ranges from 1.0 to 1.232 (Fig. 4b). The AMS data of the Huangniuling samples display mainly oblate fabrics (Fig. 4d) but also show a weak prolate fabric with the maximum axes trending SE and the minimum and intermediate axes girdling along the NE-SW direction (Fig. 4c). In addition, the degree of anisotropy of the Huangniuling samples is low, varying from 1.0 to 1.089 and mostly below $\sim 1.03$ (Fig. 4d). 
(a)

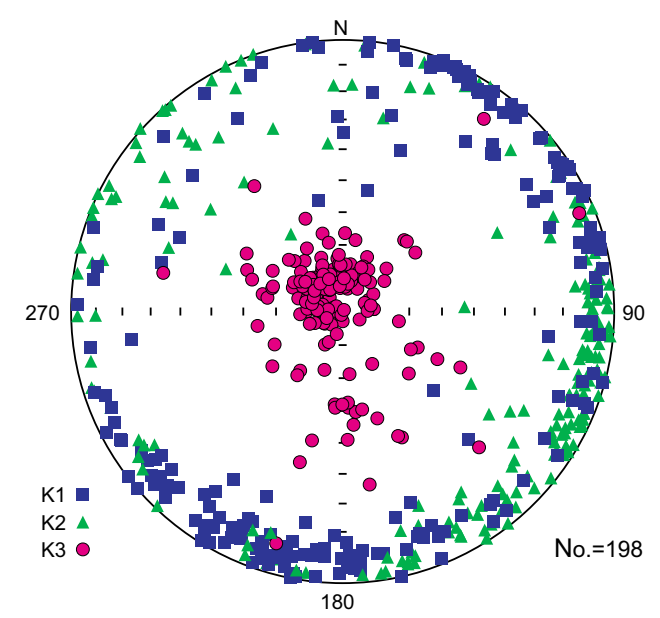

(b)

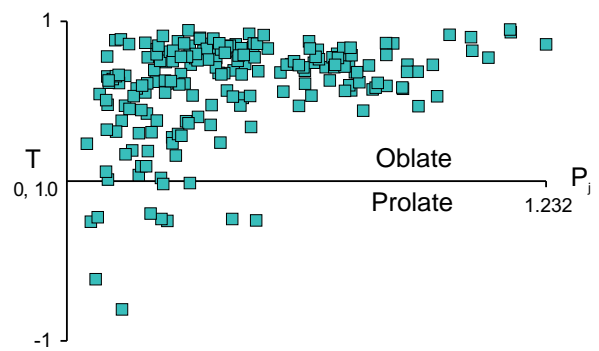

(c)

Huangniuling

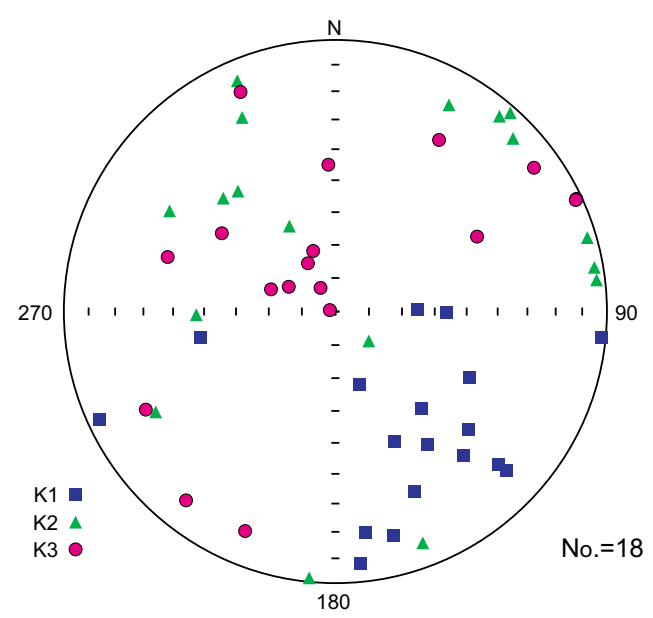

(d)

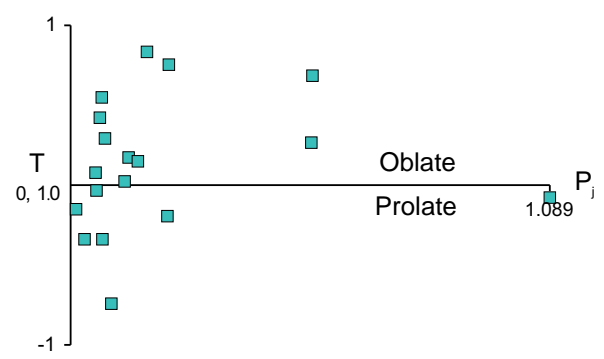

Figure 4. Anisotropy of magnetic susceptibility (AMS) data of the Youganwo Fm (a, b) and the Huangniuling Fm (c, d). $k 1, k 2$, and $k 3$ are the maximum, intermediate, and minimum axis of the anisotropy ellipsoid, respectively. Panels (a, c) show the equal area projection of these principal axes. "No." indicates the number of specimens. $T$ and $\mathrm{Pj}$ in $(\mathbf{b}, \mathbf{d})$ are the shape factor and the degree of anisotropy, respectively (Jelinek, 1981).

\subsubsection{Temperature-dependence magnetic properties and IRM}

Thermomagnetic curves of the samples show that all the low-field magnetic susceptibility values at the end of the experiments are higher than those at the beginning of the experiments, suggesting that transformation of magnetic mineral phases occurred during heating (Fig. 5a-e). Because the cooling curves generally show a rapid increase in susceptibility from 580 to $500^{\circ} \mathrm{C}$ (Fig. 5a-e), magnetite minerals were probably produced during the experiments, leading to elevated susceptibility values by the end of the experiments. The mudstone in the lower part of the Huangniuling Fm (Fig. 5a, b) and the brown grey shale of the uppermost Youganwo Fm (Fig. 5c) show overall similar features with an increase in magnetic susceptibility between 450 and $500^{\circ} \mathrm{C}$ during heating, whereas the oil shale samples show an increase in magnetic susceptibility at $\sim 250^{\circ} \mathrm{C}$ and another major increase between 400 and $450^{\circ} \mathrm{C}$ (Fig. 5d, e) during heating. For the oil shale samples, the magnetic susceptibility increase at $\sim 250^{\circ} \mathrm{C}$ (Fig. $5 \mathrm{~d}$, e) is diagnostic of hexag- onal pyrrhotite due to thermally activated vacancy ordering (Dunlop and Özdemir, 1997), and the subsequent increase in magnetic susceptibility between $450{ }^{\circ} \mathrm{C}$ and $\sim 500^{\circ} \mathrm{C}$ probably indicates the transformation of pyrrhotite to magnetite during heating (Fig. 5d, e).

IRM acquisition of the samples shows that these samples are mostly saturated at fields above $200 \mathrm{mT}$ (Fig. 5f). The demagnetization of IRMs in the backward DC fields suggests that the coercivity of the magnetic minerals is around $40 \mathrm{mT}$ (Fig. 5f). The ZFC and FC low-temperature data of the samples show that the Huangniuling mudstone and the brown grey shale of the uppermost part of the Youganwo Fm exhibit similar features that are characterized by a small difference between the ZFC and FC curves (Fig. 5g, h). In addition, the Huangniuling mudstone shows a subdued transition at ca. $120 \mathrm{~K}$ (marked with an arrow in Fig. 5g), which may indicate the presence of magnetite (Verwey, 1939; Özdemir et al., 1993). Thermal demagnetization of the composite IRM of the Huangniuling mudstone and the brown grey shale of the Youganwo Fm shows that the low coer- 

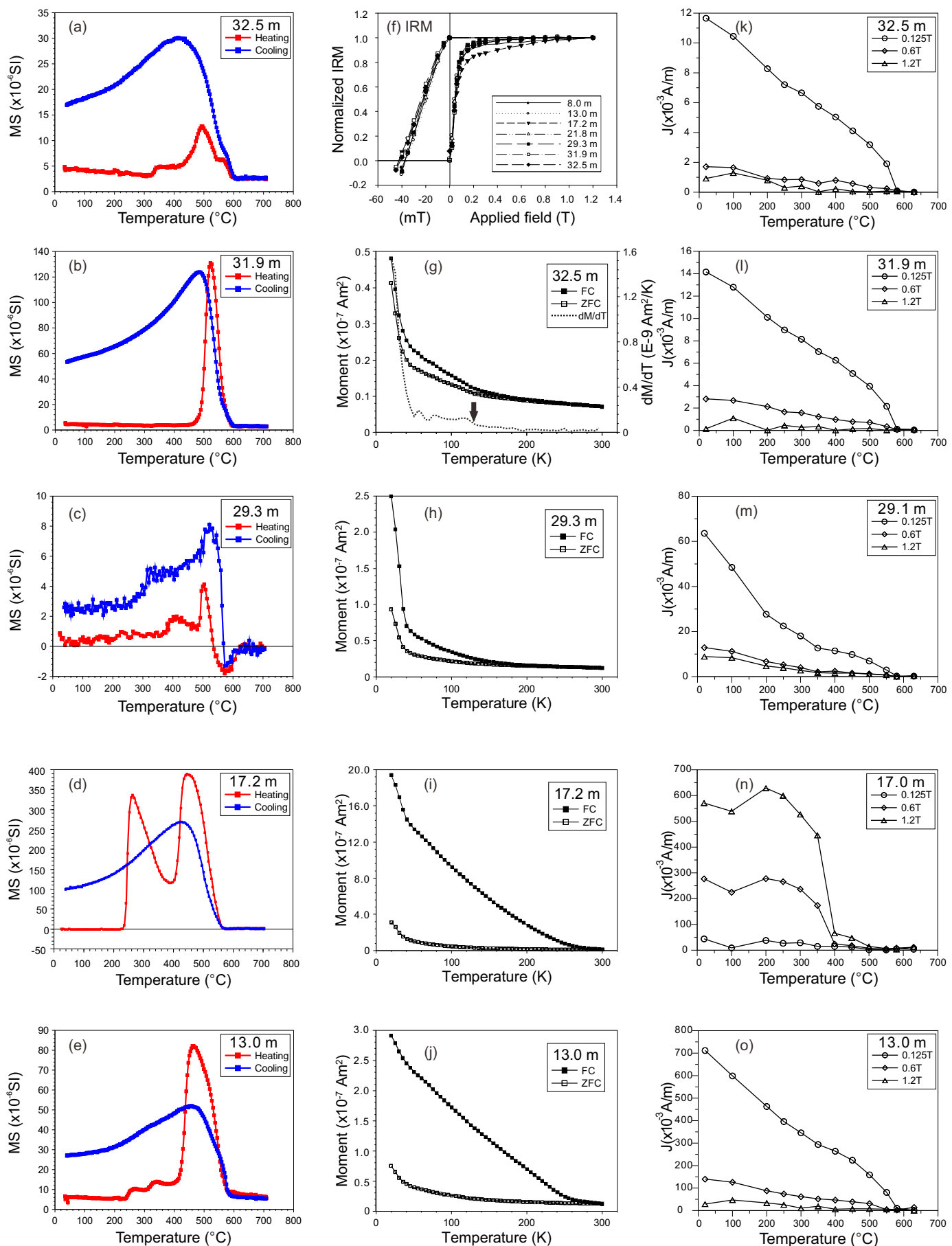

Figure 5. Rock magnetic data of samples from the Youganwo Fm and Huangniuling Fm. Panel (a-e): temperature dependence of magnetic susceptibility (MS) of samples from the Huangniuling mudstone (a, b) and from the uppermost brown grey shale (c) and the oil shale (d, e) of the Youganwo Fm during a heating-cooling cycle between room temperature and $700{ }^{\circ} \mathrm{C}$. Panel (f): IRM acquisition and the subsequent demagnetization in a backward DC field. Panel (g-j): zero-field-cooled (ZFC) and field-cooled (FC) low-temperature measurements of the representative samples. The arrow in (g) marks the subdued Verwey transition. Panel (k-o): thermal demagnetization of the composite IRM that was acquired along $z, y$, and $x$ axes in a field of $1.2,0.6$, and $0.125 T$, respectively. 
civity component $(0.125 \mathrm{~T})$ unblocked at $580^{\circ} \mathrm{C}$, confirming that magnetite is the major magnetic mineral phase in the Huangniuling mudstone and the brown grey shale of the uppermost of the Youganwo Fm. For the Youganwo oil shale, in addition to pyrrhotite, the presence of which is indicated by the rapid increase in magnetic susceptibility at $\sim 250^{\circ} \mathrm{C}$ (Fig. 5d, e), magnetite is present as well, which is evidenced by the $580^{\circ} \mathrm{C}$ unblocking temperature of the composite IRM (Fig. 5o). At some oil shale levels such as around $17.2 \mathrm{~m}$, iron sulfide phases become predominant, which is indicated by the sharp drop in the composite IRM between 350 and $400^{\circ} \mathrm{C}$ (Fig. 5n). ZFC and FC lowtemperature measurements show that there is a marked difference between the ZFC and FC curves (Fig. 5i, j), indicating the presence of pyrrhotite (Snowball and Torii, 1999). $\mathrm{The} \mathrm{Mr} / \chi$ ratio of the Youganwo oil shale is typically around $0.5 \times 10^{3}$ to $1.0 \times 10^{3} \mathrm{~A} \mathrm{~m}^{-1}$, which is low in comparison to the $\sim 70 \times 10^{3} \mathrm{~A} \mathrm{~m}^{-1}$ for greigite (Snowball and Thompson, 1990). Also, greigite tends to display little difference between ZFC and FC curves (Chang et al., 2007; Roberts et al., 2011). Therefore, greigite may not be present in Youganwo oil shale. Pyrrhotite is the dominant iron sulfide phase in the Youganwo oil shale and was likely produced during the oil shale accumulation.

\subsection{Paleomagnetic data}

Natural remanent magnetizations (NRMs) of the samples range between $3 \times 10^{-3}$ and $20 \mathrm{~mA} \mathrm{~m}^{-1}$ with the majority being on the order of $10^{-2}$ to $10^{-1} \mathrm{~mA} \mathrm{~m}^{-1}$. About half of the specimens are magnetically unstable, displaying erratic directions upon demagnetization. For the rest of the samples, the AF demagnetized samples generally show demagnetization trajectories decaying toward the origin (Fig. 6a, b, c) and the thermally demagnetized samples generally show relatively stable demagnetization trajectories below $400^{\circ} \mathrm{C}$ (Fig. 6d, e, f), above which erratic directions occur. For most samples, the linear segment of the demagnetization trajectory with coercivities $>15 \mathrm{mT}$ or with a temperature range from $\sim 150$ to $\sim 340$ or $380^{\circ} \mathrm{C}$ that decays toward the origin is regarded as a characteristic remanence (ChRM). The demagnetization data together with the rock magnetic data (Sect. 4.2.2) suggest that the remanence of the samples mainly resides in magnetite, and pyrrhotite becomes the dominant magnetic mineral phase in the Youganwo oil shale.

To obtain reliable estimates of the ChRMs, the following criteria are also used to scrutinize the data: (a) we generally accept ChRMs of higher coercivity or unblocking temperature component decaying toward the origin with at least four data points; (b) ChRMs with a maximum angular deviation (MAD) greater than $16^{\circ}$ are rejected; (c) if two samples from the same stratigraphic level yield similar ChRMs, the sample that has a better definition of the ChRM is used. Following the above treatments, we obtain reliable paleomagnetic data from 63 stratigraphic levels (see Table S1 in the Supplement).
Among these data, ChRMs from 46 stratigraphic levels have their corresponding virtual geomagnetic pole (VGP) within $45^{\circ}$ of the mean of VGPs. These 46 ChRMs show both normal and reversed polarities (Fig. 7). A reversal test was performed and passed at $95 \%$ confidence level (class "C"; McFadden and McElhinny, 1990). Therefore, the quality of the $46 \mathrm{ChRMs}$ is ranked as " $\mathrm{A}$ " and the remaining $17 \mathrm{ChRMs}$ are ranked as "B" in quality. Changes in inclinations and VGP latitudes of these ChRMs with depth are shown in Fig. 8c, d.

\section{Discussions}

\subsection{Depositional environment}

The history of depositional environmental changes in the Maoming Basin was summarized by Guo (2006). For the investigated section in this study, the upper part of the Youganwo oil shale was deposited in a semi-deep- or deeplake environment that gradually transitioned to a shallowlake environment in the uppermost section of the Youganwo Fm (Guo, 2006). The striking sedimentary rhythms are dominated by 127 to $107 \mathrm{~cm}$ cycles and $30 \mathrm{~cm}$ cycles, displaying a cycle wavelength ratio of $3.6: 1$ to $4.2: 1$, which is similar to the periodicity ratio of $4: 1$ for the long-eccentricity and the short-eccentricity cycles. The $252 \mathrm{~cm}$ cycle has a cycle wavelength about 2 times that of the 127 to $107 \mathrm{~cm}$ cycles, probably representing the harmonics of the 127 to $107 \mathrm{~cm}$ cycles. Therefore, the dominant sedimentary cycles are probably in the orbital frequency bands and the meter-scale cycles may represent the long-eccentricity cycle. Since the Youganwo oil shale was formed in a lacustrine environment (Guo, 2006), the repeated occurrence of such subtle lithological changes, as shown as the meter-scale sedimentary cycles, was probably related to fluctuating lake levels, which can cause subtle changes in deposition and thus in lithology. Fluctuations in the lake level in the Maoming Basin may have been modulated by orbital variations because the dominant sedimentary cycles appear to be in the orbital frequency bands, probably representing long- and short-eccentricity cycles. Orbital variations probably affected moisture conditions in this region, leading to wet-dry oscillations and thus fluctuations in the lake level. Relatively less or more organic matter may have been accumulated during low or high lake level periods, respectively, resulting in subtle cyclic lithological variations. The subtle lithological changes become distinctly displayed as striking sedimentary cycles on the outcrop upon weathering. The reddish beds probably correspond to depositions during low lake level periods when relatively less organic matter was accumulated.

The contact between the Youganwo Fm and the Huangniuling Fm shows gradual change from brown grey mudstones in the uppermost section of Youganwo Fm to the pale grey mudstone at the base of the Huangniuling Fm, which gradually transitions to siltstones and further to sandstones. These features suggest that the deposition was continuous at the 
(a) $31.7 \mathrm{~m}$
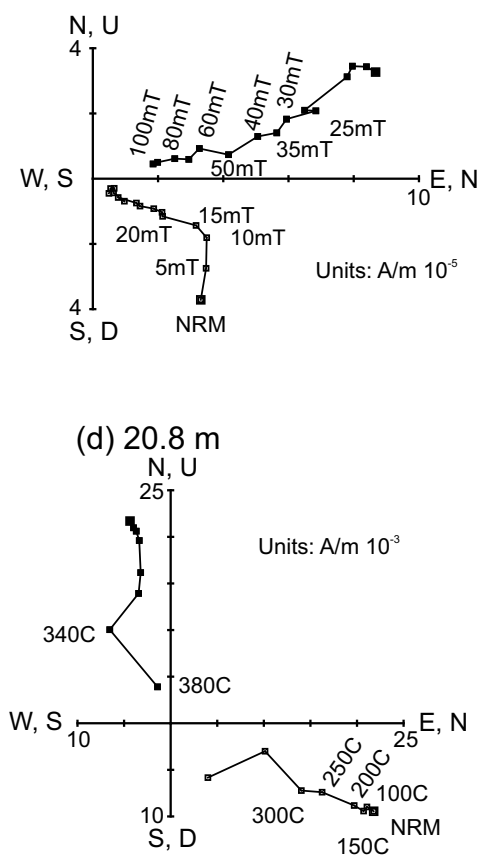

(b) $8.2 \mathrm{~m}$

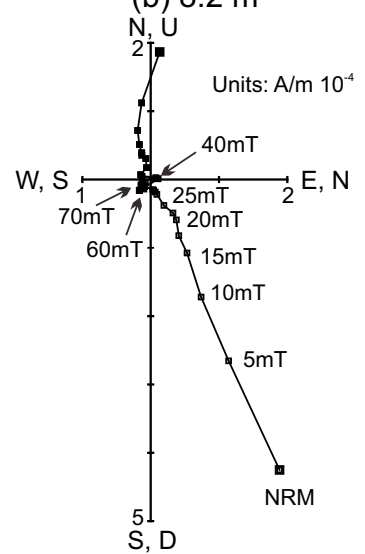

(e) $24.9 \mathrm{~m}$

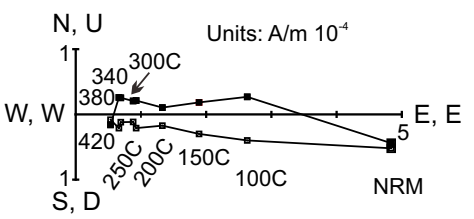

(c) $10.5 \mathrm{~m}$

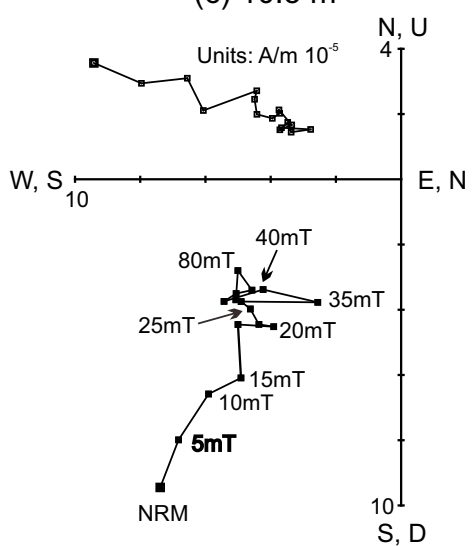

(f) $30.8 \mathrm{~m}$

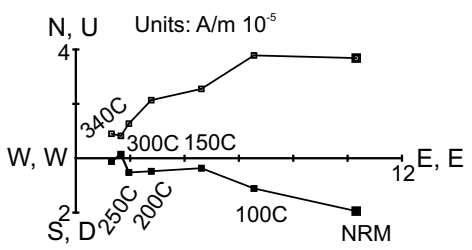

Figure 6. Representative demagnetization data of samples from the section studied. Open and closed squares indicate the vertical and horizontal components, respectively.

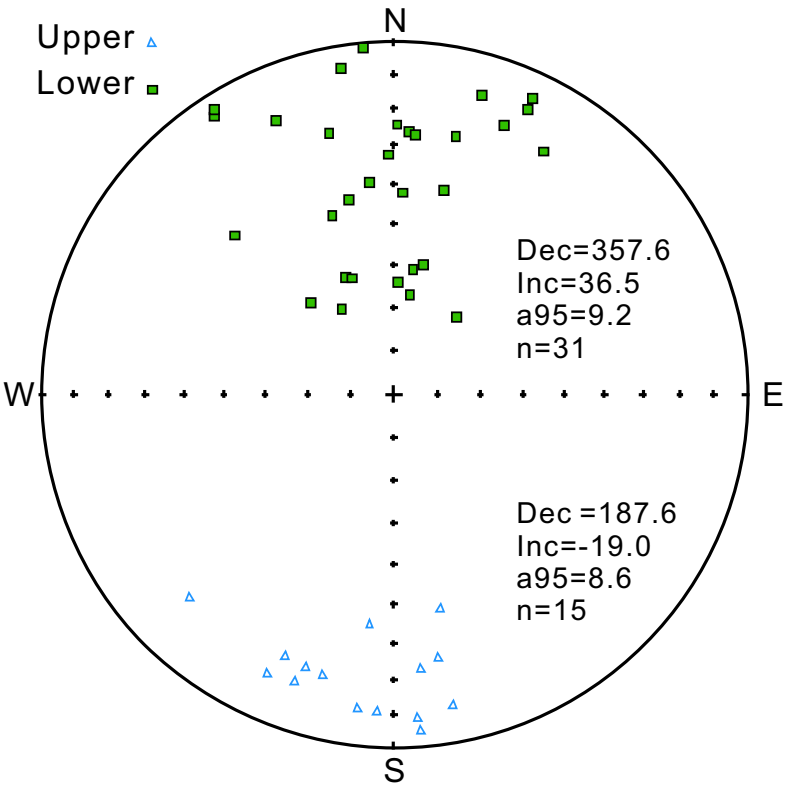

Figure 7. Characteristic remanent magnetization in stratigraphic coordinates. The solid and open symbols represent the lower and upper hemisphere projection, respectively. Dec: declination; Inc: inclination; a95: radius of cone at $95 \%$ confidence level; $n$ : number of data points; all angles are in degrees. study site when the Maoming Basin experienced the transition from a shallow lacustrine environment, as represented by the upper part of the Youganwo Fm, to a prodelta environment, as represented by the lower part of the Huangniuling Fm (Guo, 2006), while the lake level was probably dropping.

For the lower part of the Huangniuling Fm, since the sandstone and mudstone beds in a parasequence are nearly flat and extend laterally with uniform thickness for hundreds of meters, the lower part of the Huangniuling Fm was likely deposited in a prodelta to delta front or an interdistributary bay environment. Given the gradual nature of the transition from the Youganwo Fm to the Huangniuling Fm, the repeated occurrence of the parasequence in the lower part of the Huangniuling Fm was probably associated with fluctuating lake levels that may have been forced by orbital variations as well. This notion of orbital forcing is supported by the persistent pattern of rhythmic occurrence of the parasequences. This notion is also strengthened by the demonstrated orbital forcing of the deposition in marine (e.g., the Eocene-Oligocene boundary GSSP section in Italy; Jovane et al., 2006) and lacustrine (e.g., the Green River Fm; Meyers, 2008) settings during a similar time interval. For the upper part of the Huangniuling Fm, the occasional occurrence of lens-shaped channelized sandstones suggests that delta front to delta plain deposits gradually became dominant in the upper section. 
(a)

$\mathrm{Fm} /$

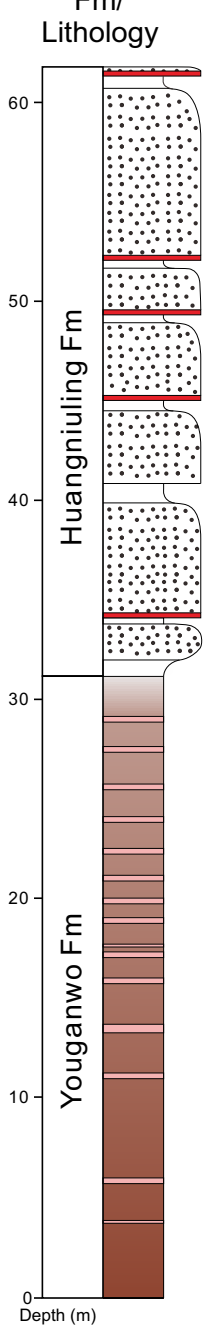

(d)

(c) VGP
latitude

(e) Polarity
zones (f) Polarity Epoch (g) (h) Chron (Stage) $\delta^{18} \mathrm{O}$

(b)
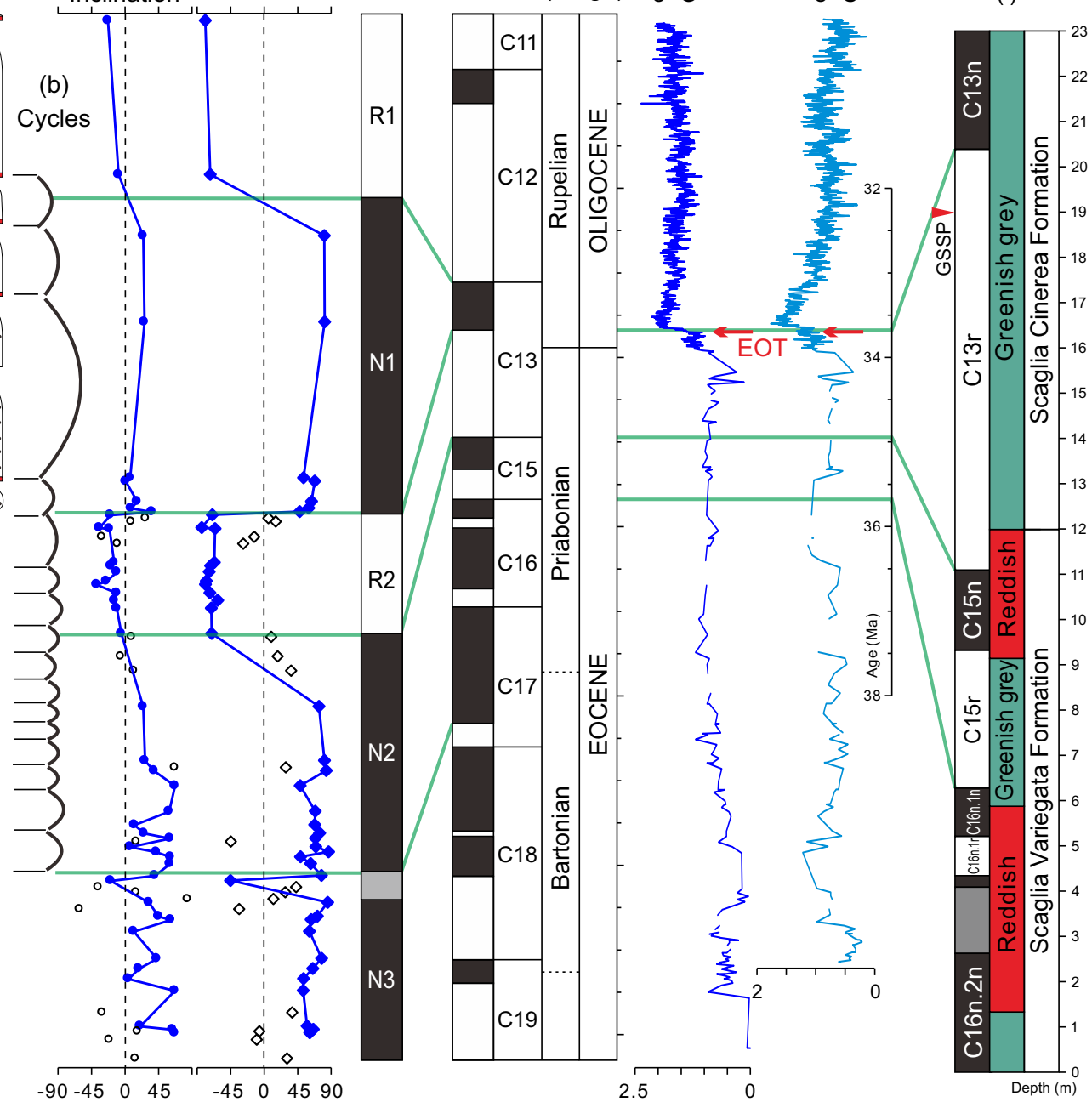

Figure 8. Integrated litho-, cyclo-, and magnetostratigraphy (a-f) of the investigated section, and the correlation with the $\delta^{18} \mathrm{O}$ and $\delta^{13} \mathrm{C}$ records (g, h) from the equatorial Pacific deep-sea sediments (ODP site 1218) (Pälike et al., 2006) as well as the chrono- and lithostratigraphy (i) of the Massignano section in Italy (the Eocene-Oligocene boundary global stratotype section and points, GSSP; Jovane et al., 2009), showing the Eocene-Oligocene climatic transition (EOT) and its precursor events. The legends for lithology and sedimentary cycles of the section studied in the Maoming Basin are the same as those in Fig. 2. In (c, d) the solid (open) symbols represent A (B)-quality ChRM data. Note that a major lithological change from the Scaglia Variegada Fm to the Scaglia Cinerea Fm occurs at $12 \mathrm{~m}$, which corresponds to the early stage of chron C13r (i), while the major lithological change at the investigated section occurs at the late stage of chron C13r (a, f).

\subsection{Definition of magnetozones}

Oil shales in the Youganwo Fm exhibit predominantly oblate AMS fabrics (Fig. 4), indicative of a depositional origin of the fabrics. Silty mudstone layers in the Huangniuling Fm also show mainly oblate AMS fabrics, and prolate fabrics occur as well, though weak. These features indicate that the depositional fabrics developed in the presence of currents flowing at a moderate speed (Tauxe, 1998), which is consistent with a deltaic depositional environment for the Huangniuling Fm. In addition, reversed polarities are present and a reversal test passed the confidence criteria (Sect. 4.3). Taken together, the occurrence of depositional fabrics, the presence of reversed polarities, and the passage of a reversal test suggest that the remanence is likely primary. Therefore, both the VGP latitudes and inclinations are used to define magnetozones of the investigated sections (Fig. 8e). Also, the definition of magnetozones is primarily based on the A-quality ChRM data, and the B-quality ChRM data are only used as a second-order constraint for intervals where A-quality data are sparse (Fig. 8c, d). In addition, a polarity zone is defined by at least two consecutive levels of similar polarities. Changes in inclinations and VGP latitudes with depth 
are largely in concert, which allows us to define two reversed polarity zones (R1 and R2) and two main normal polarity zones (N1 and N2) (Fig. 8e). Of these magnetozones, N1 and $\mathrm{R} 2$ are better defined. $\mathrm{N} 1$ is defined as occurring between 32.2 and $51.0 \mathrm{~m}$, and $\mathrm{R} 2$ is defined as occurring from 25.0 to $32.2 \mathrm{~m}$ (Fig. 8e). The section below $25.0 \mathrm{~m}$ is dominated by the normal polarities except at $\sim 10 \mathrm{~m}$, where isolated negative inclinations and VGP latitudes occur (Fig. 8c, d). Although these negative values do not occur at consecutive depths (Fig. 8c, d), the trend of a shift toward negative values in both inclinations and VGP latitudes is evident and is consistent, suggesting that a reversed polarity probably exists at $\sim 10 \mathrm{~m}$ (Fig. $8 \mathrm{e}$ ). This possible reversed polarity zone is tentatively defined as being between $\sim 11.0$ and $\sim 8.5 \mathrm{~m}$, and it separates the lower $25 \mathrm{~m}$ of the section into two short normal polarity zones, N2 and N3 (Fig. 8e).

\subsection{Major constraints on a GPTS}

The correlation of these magnetozones to the standard GPTS is not unique due to the lack of numerical ages serving as anchor points. However, several constraints exist for the investigated section. When these constraints are used collectively and in conjunction with the defined magnetozones (Fig. 8e), it is possible to establish a reliable polarity timescale for this section.

The major constraints are as follows. First, the oil shales studied contain abundant vertebrate and plant fossils (Chow and Liu, 1955; Liu, 1957; Yeh, 1958; Chow and Yeh, 1962; Li, 1975; Yu and Wu, 1983; Wang et al., 2007; Claude et al., 2012; Feng et al., 2012, 2013). In particular, the mammal fossil (Lunania cf. L. youngi) (Wang et al., 2007), which was unearthed from the studied oil shale of the Youganwo Fm, provides the most definite evidence for a late Eocene age (Wang et al., 2007; Jin et al., 2008). Accordingly, the Youganwo oil shale was formed sometime in the Priabonian Stage and/or Bartonian Stage of the Eocene, which may span magnetic chrons $\mathrm{C} 18 \mathrm{r}$ to C13r, i.e., from 41 to $34 \mathrm{Ma}$ (Fig. 8f). Second, the marked difference in lithology of the Youganwo Fm and the Huangniuling Fm suggests a drastic difference in sediment accumulation rates. The sampled Youganwo Fm consists predominantly of brown oil shales, whereas the overlying Huangniuling Fm comprises dominantly massive, pebbly coarse sandstones and siltstones. Therefore, the sediment accumulation rates for the Huangniuling Fm were much higher than those for the Youganwo Fm. In addition, although organic matter and silt content decreases upsection and grey mudstones occur in the uppermost section of the Youganwo Fm, changes in lithology within the Youganwo Fm are subtle. This suggests that the sediment accumulation rates of the Youganwo Fm studied should not change drastically. Third, the deposition between the Youganwo and Huangniuling Fms is continuous. The contact between the two formations displays a continuous, gradual change from brown grey mudstones in the uppermost section of Youganwo Fm to pale grey mudstones at the base of the Huangniuling Fm within an interval of $\sim 50 \mathrm{~cm}$. In addition, siltstones and sandstones overlying the basal pale grey mudstone exhibit a coarsening upward trend in grain size, indicating a continuous deposition during the transition from the Youganwo Fm to the Huangniuling Fm. Fourth, the characteristic sedimentary cycles of the investigated section may also be used as an additional constraint. In fact, the occurrence of sedimentary cycles is not unique in the section studied. A marine succession of a similar age in Massignano, Italy, also displays striking limestone-marl cycles (Jovane et al., 2006). Cyclic lithologic patterns are also seen in the middle Eocene oilshale-bearing lacustrine succession in the Mudurnu-Göynük Basin, Turkey (Ocakoğlu et al., 2012), the Eocene oil-shalebearing Green River formation in the United States (Meyers, 2008), and other terrestrial records of similar ages in Asia (e.g., Dupont-Nivet et al., 2007; Xiao et al., 2010). All these lithologic cycles are attributed to orbital forcing and represent orbital cycles (Jovane et al., 2006; Dupont-Nivet et al., 2007; Meyers, 2008; Xiao et al., 2010; Ocakoğlu et al., 2012). The strong lithologic expression of orbital variations in both marine and terrestrial records, particularly those containing oil shales, from widespread regions of similar ages leads us to believe that the sedimentary cycles of the section studied probably represent orbital cycles as well. In particular, the spectral analysis of magnetic susceptibility depth series of the Youganwo Fm reveals dominant sedimentary cycles with a cycle wavelength ratio of $\sim 4: 1$, suggesting that these sedimentary cycles may represent long- and shorteccentricity cycles. Therefore, these lithologic cycles can be used as an additional, first-order constraint when establishing a timescale for the section studied. Based on the definition of the magnetozones (Fig. 8 ), there are $\sim 3.5$ sedimentary cycles in N1. Because a sedimentary cycle in the Huangniuling Fm is represented by a sequence of a red layer, massive sandstone, and a thin mudstone bed, a red layer may not be readily identified at $\sim 40 \mathrm{~m}$ where the accompanying thin mudstone bed does occur (Fig. 8). Therefore, there are probably four sedimentary cycles in the N1 zone. Similarly, there are about three sedimentary cycles in the R2 zone and $\sim 8.5$ sedimentary cycles in the N2 zone (Fig. 8).

\subsection{Construction of a GPTS}

With the aforementioned four constraints, correlations between the four polarity zones (Fig. 8e) and the magnetochrons $\mathrm{C} 18 \mathrm{r}$ to $\mathrm{C} 13 \mathrm{r}$ (Fig. 8f) can be examined and unrealistic correlations can be rejected. Because polarity zones N1 and R2 are better defined than the other two polarity zones, correlation is thus found mainly between the N1 and R2 pair and the consecutive normal and reversed magnetochrons of the GPTS. To facilitate the analyses, the N2 zone is also used, but as a secondary constraint, in establishing the correlations.

The results of correlations are summarized in Table 1. With the first-order constraint that the Youganwo oil shales 
were formed in the late Eocene, i.e., from $\mathrm{C} 18$ to $\mathrm{C} 13$, six ensembles of correlations are possible (Table 1). Ensemble 1 correlates the $\mathrm{N} 1$ and $\mathrm{R} 2$ zones with $\mathrm{C} 18 \mathrm{n}$ and $\mathrm{C} 18 \mathrm{r}$, respectively. Ensemble 2 correlates the N1 and R2 zones with C17n and $\mathrm{C} 17 \mathrm{r}$, respectively. Ensemble 3 relates N1 to C16n.2n and R2 to C16r. Ensemble 4 links N1 to C16n.1n, R2 to C16n.1r, and N2 to C16n.2n. In Ensemble 5, the N1 and $\mathrm{R} 2$ zones are correlated to $\mathrm{C} 15 \mathrm{n}$ and $\mathrm{C} 15 \mathrm{r}$, respectively. Ensemble 6 correlates $\mathrm{N} 1$ to $\mathrm{C} 13 \mathrm{n}$ and $\mathrm{R} 2$ to $\mathrm{C} 13 \mathrm{r}$. The quality of each correlation is assessed by examining whether and to what extent the above four constraints are met. The correlation that satisfies most or all of the constraints is preferred and is used to establish the magnetic polarity timescale for the investigated section. For instance, Ensemble 1 is rejected because this correlation would place the majority of the Youganwo oil shale section (N2-N3), where fauna fossils of late Eocene age were discovered, in the middle Eocene (Fig. 8e, f). Ensembles 2 and 3 are rejected on the grounds that the sedimentation rate for $\mathrm{N} 1$ in the coarse sandstones is slower than or similar to that of R2 in the oil shale, which violates the second constraint. Ensemble 4 is also rejected because the sedimentation rate for the upper part of the Youganwo Fm (R2) is almost 2 times that of the lower part of the Youganwo oil shale, which is incompatible with the subtle compositional change within the Youganwo Fm studied.

For Ensemble 5, assuming that C16n.1r was not captured, probably due to its relatively short duration, the N2 zone would correlate to $\mathrm{C} 16 \mathrm{n}$. Such a correlation yields a sedimentation rate of $\sim 6.37 \mathrm{~cm} \mathrm{kyr}^{-1}$ for $\mathrm{N} 1, \sim 1.75 \mathrm{~cm} \mathrm{kyr}^{-1}$ for $\mathrm{R} 2$, and $\sim 1.51 \mathrm{~cm} \mathrm{kyr}^{-1}$ for N2 (Table 1). These sedimentation rates comply with the constraints specified in Sect. 5.2. However, the sedimentation rates of $\sim 1.51$ to $1.75 \mathrm{~cm} \mathrm{kyr}^{-1}$ are probably too fast for the investigated oil shale because oil shale in the Youganwo Fm was formed in a semi-deep- to deep-lake environment (Guo, 2006) and the lithology of the investigated interval of the Youganwo Fm is nearly monotonic, consisting of only oil shale. A pure shale unit represents a condensed time interval and should accumulate at very slow rates. Two securely dated organic-rich black shale intervals in the mid-Cretaceous could serve as a useful analog to the oil shale of the investigated section. The securely dated black shale unit at $\sim 120 \mathrm{Ma}$ is about $5 \mathrm{~m}$ thick and represents $\sim 1270 \mathrm{kyr}$ ( $\mathrm{Li}$ et al., 2008), and it was thus accumulated at a rate of $\sim 0.39 \mathrm{~cm} \mathrm{kyr}^{-1}$. Similarly, the sedimentation rates of the securely dated black shale unit at $\sim 94 \mathrm{Ma}$ (Sageman et al., 2006) are estimated to be $\sim 0.37$ to $\sim 0.50 \mathrm{~cm} \mathrm{kyr}^{-1}$. In addition, the Ensemble 5 correlation would result in a duration of $295 \mathrm{kyr}(\mathrm{C} 15 \mathrm{n})$ for the N1 zone and $411 \mathrm{kyr}$ for the R2 zone. Because there are $\sim 4$ and $\sim 3$ sedimentary cycles in the $\mathrm{N} 1$ zone and the R2 zone, respectively, the sedimentary cycle in the $\mathrm{N} 1$ zone and the $\mathrm{R} 2$ zone would represent a $\sim 74$ and $\sim 137$ kyr cycle, respectively. The $\sim 137 \mathrm{kyr}$ cycle in the R2 zone could be a result of modulation by short eccentricity of orbital variations. However, the $\sim 70 \mathrm{kyr}$ cycle in the N1 zone is not in the frequency band of orbital variations and its

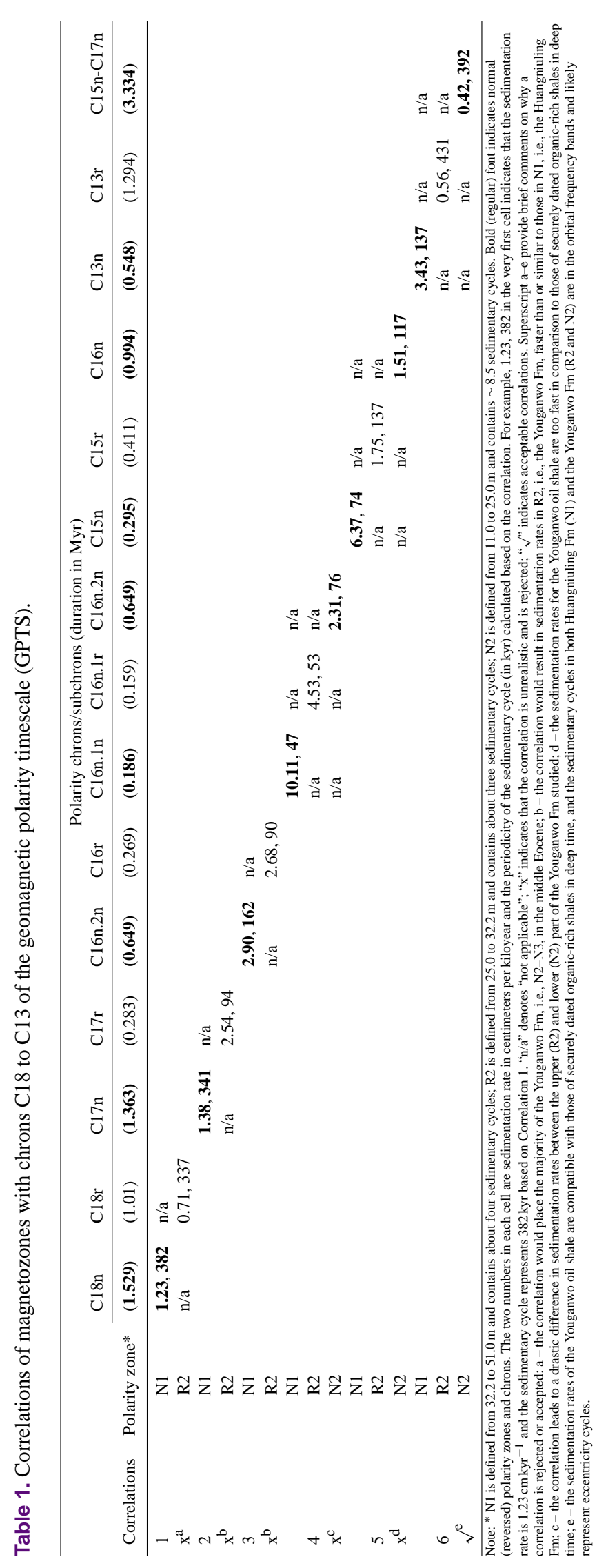


origin is thus difficult to interpret. Therefore, Ensemble 5 is rejected as well.

Ensemble 6 satisfies the constraints on sedimentation rates for the Huangniuling $\mathrm{Fm}$ and the Youganwo Fm. Also, the sedimentation rates of 0.42 to $0.56 \mathrm{~cm} \mathrm{kyr}^{-1}$ for the Youganwo Fm (Table 1) are compatible with those of the securely dated, organic-rich black shales in the midCretaceous. Furthermore, this correlation would result in durations of the N1, R2, and $\mathrm{N} 2$ zones that are largely comparable to those estimated from sedimentary cycles. With the Ensemble 6 correlation, the N1, R2, and N2 zones would represent $\sim 548, \sim 1294$, and $\sim 3334 \mathrm{kyr}$, respectively. Since the N1 zone contains about four sedimentary cycles (Fig. 8a, b), each cycle would represent a $\sim 137 \mathrm{kyr}$ cycle, which is similar to the short-eccentricity cycle E2 (95 to $125 \mathrm{kyr}$ ). Similarly, since there are about three sedimentary cycles in the R2 zone (Fig. 8a, b), each sedimentary cycle would represent a $\sim 431 \mathrm{kyr}$ cycle, which is similar to the long-eccentricity cycle E1 (405 to $413 \mathrm{kyr}$ ). As an additional check, the duration of the sedimentary cycles within the $\mathrm{N} 2$ zone is calculated. There are $\sim 8.5$ sedimentary cycles in the $\mathrm{N} 2$ zone representing $\sim 3334 \mathrm{kyr}$, and thus each sedimentary cycle has a duration of $392 \mathrm{kyr}$, which is similar to the periodicity of long-eccentricity cycle E1. Therefore, the sedimentary cycles in the Youganwo Fm are consistently shown as representing the long-eccentricity cycles. It is reasonable that the sedimentary cycles in N1, i.e., Huangniuling Fm, represent short-eccentricity E2 and sedimentary cycles in R2 represent long-eccentricity E1 because the sedimentation rate of the Huangniuling Fm is much higher than that of the Youganwo Fm and orbital cycles with shorter durations can be recorded in the Huangniuling Fm. Indeed, among these six ensembles, only Ensemble 6 can yield periodicities of all the sedimentary cycles, which are from different parts of the section, in the orbital frequency band within uncertainties (Table 1). Thus, taken together, Ensemble 6 can satisfy different aspects of major constraints within uncertainties and thus is acceptable.

Analyses of the six possible correlations lead to a conclusion that only Ensemble 6 correlation offers the most realistic scenario. Therefore, the Ensemble 6 correlation is employed to establish a chronological framework for the section studied (Fig. 8e, f). With this chronological framework, the transition from the Youganwo Fm to the Huangniuling Fm took place within magnetochron C13r (Fig. 8). Because the transition is represented by a $\sim 50 \mathrm{~cm}$ thick, mudstone-dominated interval and the $\mathrm{C} 13 \mathrm{n}-\mathrm{C} 13 \mathrm{r}$ boundary (33.705 Ma) occurs at $\sim 70 \mathrm{~cm}$ above the top of the transitional interval, the age of the onset of the transition can be determined by estimating the duration of the $\sim 1.2 \mathrm{~m}$ thick interval. There are two ways to estimate the duration of the $1.2 \mathrm{~m}$ thick interval. One is to extrapolate the sedimentation rate of $\sim 0.56 \mathrm{~cm} \mathrm{kyr}^{-1}$ for the uppermost part of the Youganwo Fm, i.e., the R2 zone. This would lead to an estimate of $\sim 210 \mathrm{kyr}$ and the onset of the transition is then estimated to be at $\sim 33.915 \mathrm{Ma}$. The sec- ond approach is to treat the $1.2 \mathrm{~m}$ thick interval as the upper part of the long-eccentricity cycle in the uppermost section of the Youganwo Fm (Fig. 8a, b). This results in an estimate of $\sim 140 \mathrm{kyr}$ for the $1.2 \mathrm{~m}$ thick interval and an onset age of $\sim 33.845$ Ma. Taking the average of the above two estimates, we obtain a mean age of 33.88 Ma for the onset of the transition. In summary, the constructed timescale represents a significantly refined chronology for the Paleogene strata in the Maoming Basin and provides the tightest possible constraints on the timing of the onset of the transition from a lacustrine environment to a deltaic environment in the Maoming Basin.

\subsection{Paleoclimatic implications}

The rapid transition from a lacustrine environment to a deltaic environment could be related to global climate change. In the late Paleogene, the Earth's climate underwent a major transition from greenhouse to icehouse that climaxed at the Eocene-Oligocene boundary (Zachos et al., 2001). This climatic transition was accompanied by rapid ice sheet growth in Antarctica (e.g., DeConto and Pollard, 2003; Coxall et al., 2005; Goldner et al., 2014) and was characterized by pronounced global cooling (e.g., Zanazzi et al., 2007; Liu et al., 2009; Bohaty et al., 2012; Hren et al., 2013). The Eocene-Oligocene transition (EOT) was dated to 33.714 Ma (Jovane et al., 2006) from the marine succession in Massignano, Italy, which is the Global Stratotype Section and Point (GSSP) for the Eocene-Oligocene boundary. Studies of the equatorial Pacific records constrain the EOT at $\sim 33.79 \mathrm{Ma}$ (Pälike et al., 2006) or $33.89 \mathrm{Ma}$ (Westerhold et al., 2014). The rapid transition from a lacustrine environment to a deltaic environment in the Maoming Basin is dated to $33.88 \mathrm{Ma}$, which coincides well with the timing of the EOT determined from marine records. The close timing suggests a strong link between the drastic environmental transition in the Maoming Basin and the EOT (Fig. 8f). The dramatic shift from a lacustrine to a deltaic environment in the Maoming Basin suggests that low-latitude Asia likely underwent a transition in regional hydrological cycle from humid to dry conditions in response to global cooling at the EOT. As dry conditions become prevalent, the lake level likely dropped and the lake area shrunk. The prevailing drying conditions together with global cooling during EOT probably promoted upland erosion and supplied abundant sediments to the shrinking lake, leading to the rapid increase in sediment accumulation rates after the dramatic environmental change. The dry conditions perhaps persisted in low-latitude Asia after the dramatic environmental change as the global climate continued to deteriorate following the rapid, severe, and widespread climatic transition at the Eocene-Oligocene boundary (Fig. 8f). This persistent dry condition is indicated by the accumulation of the sandstone-dominated Huangniuling Fm in the Maoming Basin at comparatively higher sedimentation rates. Indeed, similar depositional environmental change and an increase in sedimentation rates between 34.5 
and $31 \mathrm{Ma}$ are also observed in the Xining Basin and the EOT is considered as a possible cause (Dai et al., 2006).

The new, significantly refined chronology also indicates that the striking sedimentary cycles in both the Youganwo Fm and the Huangniuling Fm likely represent eccentricity cycles. The recognition of the eccentricity signal suggests that sedimentation in the Maoming Basin during this time interval may have been modulated by orbital variations, probably via lake level fluctuations at orbital frequency. The occurrence of eccentricity signals in the records is consistent with the fact the Maoming Basin is situated in the low-latitude areas that are sensitive to orbital variations at eccentricity frequency bands. Indeed, the modulation of orbital variations in sedimentation appeared to be widespread during this time interval. The long- and short-eccentricity signals are also detected from the Eocene-Oligocene Massignano section in Italy (Jovane et al., 2006). The eccentricity signals are also found in other marine successions (e.g., Westerhold et al., 2014) and lacustrine deposits (e.g., Meyers, 2008; Okacoğlu et al., 2012) of similar ages. Therefore, the drastic environmental change in the Maoming Basin during the EOT represents the terrestrial responses in low-latitude Asia to the EOT that may be superimposed on the long-term variations at orbital frequency. The investigated section in the Maoming Basin thus likely faithfully records the impacts of the EOT on low-latitude Asia.

Another notable feature is the different timings of the major lithologic changes in the Maoming terrestrial record and the marine record in Italy. In the GSSP section of Italy, the rapid lithologic change occurred at early stage of chron C13r, representing a precursor event of the EOT (Jovane et al., 2009) (Fig. 8i), while the main lithologic change in the Maoming Basin took place at the late stage of chron 13r, representing the major event of the EOT (Fig. 8a-f). This feature may indicate leads or lags of major environmental changes in the terrestrial and marine realms. The significantly refined chronology of the Maoming record from low-latitude Asia could potentially help us to better understand the teleconnection mechanism for the major global climatic transition across the Eocene-Oligocene boundary.

\section{Conclusions}

We have carried out a detailed stratigraphic and paleomagnetic investigation of the upper Paleogene succession in the Maoming Basin, southern China. The investigated succession comprises oil-shale-dominated Youganwo Fm and the overlying sandstone-dominated Huangniuling Fm. Both the Youganwo Fm and the overlying Huangniuling Fm exhibit striking sedimentary rhythms. The sedimentary rhythms of the Youganwo Fm are well expressed by the high-resolution magnetic susceptibility data, and spectral analysis of the magnetic susceptibility depth series reveals that the dominant meter-scale sedimentary cycles are in orbital frequency bands. The sedimentary rhythms in the Huangniuling Fm are characterized by the repeated occurrence of a parasequence containing a red sandstone layer, massive coarse sandstones, and a relatively thin mudstone bed. New paleomagnetic results, together with the lithologic and fossil age data, allow us to establish a magnetostratigraphy for the section studied that constrains the striking sedimentary cycles of the Youganwo Fm and Huangniuling Fm to long- and short-eccentricity cycles, respectively. Taken together, a significantly refined chronological framework is established for the investigated succession.

The contact between the Youganwo Fm and the Huangniuling Fm is represented by a $50 \mathrm{~cm}$ interval that shows a gradual change from dark grey mudstone in the uppermost section of the Youganwo Fm to the grey mudstone and siltstones with a coarsening upward trend in grain size at the base of the Huangniuling Fm. This interval represents a major environment change from a lacustrine to a deltaic environment in the Maoming Basin, and its onset is dated to $\sim 33.88 \mathrm{Ma}$. The timing of the onset of the dramatic environmental change is remarkably similar to that of the Eocene-Oligocene transition (EOT) that is dated to 33.7 to $33.9 \mathrm{Ma}$ from various marine records. The synchroneity suggests a strong link between these two events and implies that the rapid environmental change in the Maoming Basin most likely represents terrestrial responses to the global cooling associated with the EOT. This notion is strengthened by the subsequent occurrence of the persistently prolonged dry conditions, as represented by the sandstone-dominated Huangniuling Fm, following the rapid environment change coincident with the EOT. These features are highly compatible with the continued deteriorating conditions after the EOT.

In addition, this study demonstrates that it is possible to construct a refined chronological framework for a terrestrial record by integrating multiple constraints synergistically from magnetostratigraphic, lithologic, biostratigraphic, and perhaps cyclostratigraphic data. For this study, six possible correlations between magnetozones and the standard GPTS are examined and accepted or rejected using four different types of constraints (Table 1). The robustness of the accepted correlation is thus dependent on how stringent and/or reliable these constraints are. In this study, although Ensemble 6 is considered as the most probable correlation after examining all six possible scenarios, constraints derived from the currently available data may not be stringent enough for a definite choice of Ensemble 6. For example, the repeated occurrence of parasequences in the upper part of the Huangniuling Fm has not been quantitatively assessed to show convincingly that these parasequences represent orbital cycles. Also, the difference in sedimentation rates of oil shale between Ensembles 5 and 6 - with the rate of Ensemble 5 being 2-3 times that of Ensemble 6 - may not be sufficiently large to differentiate between these two ensembles. Therefore, it would be beneficial to acquire more late Paleogene terrestrial records from other parts of low-latitude Asia in fu- 
ture studies. It would also be interesting to test whether the major environmental change in low-latitude Asia truly coincides with the main EOT event or represents responses to a precursor event of EOT. Despite the limitations of the present study, the lack of detailed terrestrial records near the EoceneOligocene boundary in continental southeast Asia makes the results of this study an important contribution to the understanding of the impacts of the major climatic transition at the end of Eocene on the environment in low-latitude Asia.

\section{The Supplement related to this article is available online at doi:10.5194/cp-12-255-2016-supplement.}

Acknowledgements. This study was supported by the National Natural Science Foundation of China (nos. 41210001, 41372002, 41274071, 41230208, 41321062, 41528201), the National Basic Research Program of China (no. 2012CB822000), and the Fundamental Research Funds for the Central Universities (20620140389). We thank Shipeng Wang for field assistance, and Mike Jackson, Qingsong Liu, and Xiumian $\mathrm{Hu}$ for helpful discussions. Bin Wen, Congcong Gai, and Shuangchi Liu helped with rock magnetic experiments at the Paleomagnetism and Geochronlogy Laboratory, Chinese Academy of Sciences. We are grateful to reviewers Alexis Licht, Christian Rolf, and Luigi Jovane, whose comments were helpful in improving the manuscript.

Edited by: H. Goosse

\section{References}

Aleksandrova, G. N., Kodrul, T. M., Liu, X. Y., Song, Y. S., and Jin, J. H.: Palynological characteristics of the upper part of the Youganwo Formation and lower part of the Huangniuling Formation, Maoming Basin, South China, in: Proceedings of the 2nd Sino-Russian Seminar on Evolution and Development of Eastern Asia Flora based on Palaeobotanical Data, 3-15, Guangzhou, China, School of Life Sciences, Sun Yat-sen University, Guangzhou, China, 2012.

Bohaty, S. M., Zachos, J. C., and Delaney, L.M.: Foraminiferal $\mathrm{Mg} / \mathrm{Ca}$ evidence for Southern Ocean cooling across the EoceneOligocene transition, Earth Planet. Sc. Lett., 317-318, 251-261, 2012.

Bureau of Geology and Mineral Resources of Guangdong Province (BGMRGP): Regional Geology of Guangdong Province, Geological Publishing House, Beijing, 1988 (in Chinese with English abstract).

Bureau of Geology and Mineral Resources of Guangdong Province (BGMRGP): Stratigraphy (Lithostratic) of Guangdong Province, China University of Geosciences Press, Wuhan, 1996 (in Chinese).

Chang, L., Robert, A. P., Rowan, C. J., Tang, Y., Pruner, P., Chen, Q., and Horng, C. S.: Low-temperature magnetic properties of greigite $\left(\mathrm{Fe}_{3} \mathrm{~S}_{4}\right)$, Geochem. Geophy. Geosys., 10, Q01Y04, doi:10.1029/2008GC002276, 2007.
Chow, M. C.: On some Eocene and Oligocene mammals from Kwangsi and Yunnan, Verterbrata Palasiatica, 1, 201-214, 1957 (in Chinese with English abstract).

Chow, M. C. and Liu, C. L.: A new anosterine turtle from Maoming, Kwangtung, Acta Palaeontol. Sin., 3, 275-282, 1955 (in Chinese with English abstract).

Chow, M. C. and Yeh, H. K., A new emydid from the Eocene of Maoming, Kwangtung, Vertebrat. Palasiatic., 6, 225-229, 1962 (in Chinese with English abstract).

Claude, J., Zhang, J. Y., Li, J. J., Mo, J. Y., Kuang, X. W., and Tong, H. Y.: Geoemydid turtles from the Late Eocene Maoming basin, southern China, Bull. Soc. Géol. France, 183, 641-651, 2012.

Coxall, H. K., Wilson, P. A., Pälike, H., Lear, C. H., and Backman, J.: Rapid stepwise onset of Antarctic glaciation and deeper calcite compensation in the Pacific Ocean, Nature, 433, 53-57, 2005.

Cotton, L. J. and Pearson, P. N.: Extinction of larger benthic foraminifera at the Eocene/Oligocene boundary, Palaeogeogr. Palaeocl., 311, 281-296, 2011.

Dai, S., Fang, X., Dupont-Nivet, G., Song, C., Gao, J., Krijgsman, W., Langereis, C., and Zhang, W.: Magnetostratigraphy of Cenozoic sediments from the Xining Basin: Tectonic implications for the northeastern Tibetan Plateau, J. Geophys. Res., 111, B11102, doi:10.1029/2005JB004187, 2006.

Danilov I. G., Syromyatnikova E. V., Skutschas P. P., Kodrul T. M., and Jin J. H.: The first "True" Adocus (Testudines, Adocidae) from the Paleogene of Asia, J. Vertebr. Paleontol., 33, 10711080, 2013.

DeConto, R. M. and Pollard, D.: Rapid Cenozoic glaciation of Antarctica induced by declining atmospheric $\mathrm{CO}_{2}$, Nature, 421, 245-249, 2003.

Dunlop, D. J. and Özdemir, Ö.: Rock Magnetism: Fundamentals and Frontiers, Cambridge Univ. Press, Cambridge, UK, 573 pp., 1997.

Dupont-Nivet, G., Krijgsman, W., Langereis, C. G., Abels, H. A., Dai, S., and Fang, X. M.: Tibetan plateau aridification linked to global cooling at the Eocene - Oligocene transition, Nature 445, 635-638, 2007.

Feng, X. X., Oskolski, A., and Jin, J.H.: Eocene dicotyledonous wood, Bischofia maomingensis sp. nov. from Maoming Basin, South China, Rev. Palaeobot. Palyno., 174, 101-105, 2012.

Feng, X. X., Tang, B., Kodrul, T. M., and Jin, J. H.: Winged fruits and associated leaves of Shorea (Dipterocarpacesa) from the late Eocence of South China and their phytogeogrpahic and paleoclimatic implications, Am. J. Bot., 100, 574-581, 2013.

Fischer, A. G.: Orbital cyclicity in Mesozoic strata, in: Cycles and Events in Stratigraphy, edited by: Einsele, G., Ricken, W., and Seilacher, A., Springer-Verlag, Berlin, 48-62, 1991.

Goldner, A., Herold, N., and Huber, M.: Antarctic glaciation caused ocean circulation changes at the Eocene-Oligocene transition, Nature, 511, 574-577, doi:10.1038/nature13597, 2014.

Guo, M.: Characteristics and mineralization controlling factors of oil shale in Maoming Basin, MS Thesis, Jilin University, 86 pp., 2006.

Hren, M. T., Sheldonc, N. D., Grimesd, S. T., Collinsone, M. E., Hookerf, J. J., Buglerd, M., and Lohmannc, K. C.: Terrestrial cooling in Northern Europe during the Eocene-Oligocene transition, P. Natl. Acad. Sci. USA, 110, 7562-7567, 2013. 
Huang, X. and Qi, T.: Notes on Late Eocene Tapiroids from the Lunan Basin, eastern Yunnan, Verterbrata Palasiatica, 20, 315326, 1982 (in Chinese with English abstract).

Huang, X. S.: New emoropid (Mammalia, Perissodactyla) remains from the middle Eocene of Yuanqu Basin, Verterbrata Palasiatica, 40, 286-290, 2002 (in Chinese with English abstract).

Jelinek, V.: Characterization of the magnetic fabrics of rocks, Tectonophysics, 79, 63-67, 1981.

Jin, J. H.: On the age of the Youganwo Formation in the Maoming Basin, Guangdong Province, J. Stratigr., 32, 47-50, 2008 (in Chinese with English abstract).

Jovane, L., Florindo, F., Sprovieri, M., and Pälike, H.: Astronomic calibration of the late Eocene/early Oligocene Massignano section (central Italy), Geochem. Geophy. Geosy. 7, Q07012, doi:10.1029/2005GC001195, 2006.

Jovane, L., Coccioni, R., Marsili, A., and Acton, G.: The late Eocene greenhouse-icehouse transition: observations from the Massignano global stratotype section and point (GSSP), Geol. Soc. Am., Special Paper, 452, 149-168, 2009.

Kirschvink, J. L.: The least-squares line and plane and the analysis of paleomagnetic data, Geophys. J. Roy. Astr. S., 62, 699-718, doi:10.1111/j.1365-246X.1980.tb02601.x, 1980.

Li, C. and Ting, S.: The Paleogene mammals of China, Bulletin of Carnegie Museum of Natural History, 21, 1-93, 1983 (in Chinese with English abstract)

Li, J. L.: New materials of Tomistoma petrolica Yeh from Maoming, Guangdong, Vertebrata Palasiatica, 13, 190-194, 1975 (in Chinese).

Li, Y. X., Bralower, T. J., Montanez, I. P., Osleger, D. A., Arthur, M. A., Bice, D. M., Herbert, T. D., Erba, E., and Premoli-Silva, I.: Toward an orbital chronology for the early Aptian Oceanic Anoxic Event 1a (OAE1a, 120 Ma), Earth Planet. Sc. Lett., 271, 88-100, doi:10.1016/j.epsl.2008.03.055, 2008.

Licht, A. van Cappelle, M., Abels, H. A., Ladant, J.-B., TrabuchoAlexandre, J., and France-Lanord, C.: Asian monsoons in a late Eocene greenhouse world, Nature, 513, 501-506, doi:10.1038/nature13704, 2014.

Licht, A., Boura, A., De Franceschi, D., Utescher, T., Sein, C., and Jaeger, J.-J.: Late middle Eocene fossil wood of Myanmar: Implications for the landscape and the climate of the Eocene Bengal Bay, Rev. Palaeobot. Palyno., 216, 44-54, 2015.

Liu, X. T.: A new fossil cyprinid fish from Maoming, Kwangtung, Vertebrata Palasiatica, 1, 151-153, 1957 (in Chinese with English abstract).

Liu, Z. H., Pagani, M., Zinniker, D., DeConto, R., Huber, M., Brinkhuis, H., Shah, S. R., Leckie, R. M., and Pearson, A.: Global cooling during the Eocene-Oligocene climate transition, Science, 323, 1187-1190, 2009.

Lowrie, W.: Identification of ferromagnetic minerals in a rock by coercivity and unblocking temperature properties, Geophys. Res. Lett., 17, 159-162, 1990.

Lurcock, P. C. and Wilson, G. S.: PuffinPlot: A versatile, userfriendly program for paleomagnetic analysis, Geochem. Geophy. Geosys., 13, Q06Z45, doi:10.1029/2012GC004098, 2012.

Mader, D., Cleaveland, L., Bice, D., Montanari, A., and Koeberl, C.: High-resolution cyclostratigraphic analysis of multiple climate proxies from a short Langhian pelagic succession in the Conero Riveiera, Ancona (Italy), Paleogeogr. Paleocl., 211, 325344, 2004.
McFadden, P. L. and McElhinny, M. W.: Classification of the reversal test in palaeomagnetism, Geophys. J. Int., 103, 725-729, 1990.

Meyers, S. R.: Resolving Milankovitchian controversies: The Triassic Latemar Limestone and the Eocene Green River Formation, Geology, 36, 319-322, doi:10.1130/G24423A.1, 2008.

Muller, R. A. and MacDonald, J. G.: Ice ages and astronomical causes: Data, spectral analysis, and mechanisms, Springer Praxis, Berlin, 2000.

Ocakoğlu, F., Açıkalın, S., Yılmaz, I. Ö., Safak, Ü., and Gökçeoglu, C.: Evidence of orbital forcing in lake-level fluctuations in the Middle Eocene oil shale-bearing lacustrine successions in the Mudurnu-Göynük Basin, NW Anatolia (Turkey), J. Asian Earth Sci., 56, 54-71, 2012.

Ogg, J. G.: Chapter 5: Geomagnetic Polarity Time Scale, in: The Geologic Time Scale 2012, edited by: Gradstein, F. M., Ogg, J. G., Schmitz, M. D., and Ogg, G. M., Elsevier, Amsterdam, 85$113,2012$.

Oskolski, A. A., Feng, X. X., and Jin, J. H.: Myrtineoxylon gen. nov.: The first fossil wood record of the tribe Myrteae (Myrtaceae) in eastern Asia, Taxon, 62, 771-778, 2013.

Özdemir, Ö., Dunlop, D. J., and Moskowitz, B. M.: The effect of oxidation on the Verwey transition in magnetite, Geophys. Res. Lett., 20, 1671-1674, doi:10.1029/93GL01483, 1993.

Pälike, H., Norris, R. D., Herrle, J. O., Wilson, P. A., Coxall, H. K., Lear, C. H., Shackleton, N. J., Tripati, A. K., and Wade, B. S.: The Heartbeat of the Oligocene Climate System, Science, 314, 1894-1898, doi:10.1126/science.1133822, 2006.

Pälike, H., Lyle, M. W., Nishi, H., Raffi, I., Ridgwell, A., Gamage, K., Klaus, A., Acton, G., Anderson, L., Backman, J., Baldauf, J., Beltran, C., Bohaty, S. M., Bown, P., Busch, W., Channell, J. E. T., Chun, C. O. J., Delaney, M., Dewangan, P., Dunkley Jones, T., Edgar, K. M., Evans, H., Fitch, P., Foster, G. L., Gussone, N., Hasegawa, H., Hathorne, E. C., Hayashi, H., Herrle, J. O., Holbourn, A., Hovan, S., Hyeong, K., Iijima, K., Ito, T., Kamikuri, S.-I., Kimoto, K., Kuroda, J., Leon-Rodriguez, L., Malinverno, A., Moore Jr., T. C., Murphy, B. H., Murphy, D. P., Nakamura, H., Ogane, K., Ohneiser, C., Richter, C., Robinson, R., Rohling, E. J., Romero, O., Sawada, K., Scher, H., Schneider, L., Sluijs, A., Takata, H., Tian, J., Tsujimoto, A., Wade, B. S., Westerhold, T., Wilkens, R., Williams, T., Wilson, P. A., Yamamoto, Y., Yamamoto, S., Yamazaki, T., and Zeebe, R. E.: A Cenozoic record of the equatorial Pacific carbonate compensation depth, Nature, 488, 609-614, doi:10.1038/nature11360, 2012.

Pearson, P. N., McMillan, I. K., Wade, B. S., Dunkley Jones, T., Coxall, H. K., Bown, P. R., and Lear, C.H.: Extinction and environmental change across the Eocene-Oligocene boundary in Tanzania, Geology, 36, 179-182, 2008.

Prothero, D. R.: The late Eocene-Oligocene extinctions, Annu. Rev. Earth Pl. Sc., 22, 145-165, 1994.

Qiu, Z. X. and Wang, B.: Paracerathere fossils of China, Palaeontoligca Sinica, New Ser. C, 29, 1-188, 2007 (in Chinese with English abstract).

Quan, C., Liu, Y.-S. C., and Utescher, T.: Eocene monsoon prevalence over China: a paleobotanical perspective, Palaeogeogr. Palaeocl., 365-366, 302-311, 2012.

Quan, C., Liu, Z. H., Utescher, T., Jin, J. H., Shu, J. W., Li, Y. X., and Liu, Y.-S. C: Revisiting the Paleogene climate pattern of East Asia: A synthetic review, Earth-Sci. Rev., 139, 213-230, 2014. 
Roberts, A. P., Chang, L., Rowan, C. J., Horng, C.-S., and Florindo, F.: Magnetic properties of sedimentary greigite $\left(\mathrm{Fe}_{3} \mathrm{~S}_{4}\right)$ : An update, Rev. Geophys., 49, RG1002, doi:10.1029/2010RG000336, 2011.

Russell, D. E. and Zhai R. J.: The Paleogene of Asia: mammals and stratigraphy, Memoires Mus. Natl. Natl. Hist., 52, 1-490, 1987.

Sageman, B. B., Meyers, S. R., and Arthur, M. A.: Orbital time scale and new $\mathrm{C}$-isotope record for Cenomanian-Turonian boundary stratotype, Geology, 34, 125-128, doi:10.1130/G22074.1, 2006.

Shukla, A., Mehrotra, R. C., Spicer, R. A, Spicer, T. E. V., and Kumara, M.: Cool equatorial terrestrial temperatures and the South Asian monsoon in the Early Eocene: Evidence from the Gurha Mine, Rajasthan, India, Palaeogeogr. Palaeocl., 412, 187-198, 2014.

Skutschas P. P., Danilov I. G., Kodrul T. M., and Jin J. H.: The First Discovery of an Alligatorid (Crocodylia, Alligatoroidea, Alligatoridae) in the Eocene of China, J. Vertebr. Paleontol., 34, 471476, 2014.

Snowball, I. and Thompson, R.: A stable chemical remanence in Holocene sediments, J. Geophys. Res., 95, 4471-4479, 1990.

Snowball, I. F. and Torii, M.: Incidence and significance of magnetic iron sulphides in Quaternary sediments and soils, in: Quaternary Climates, Environments and Magnetism, edited by: Maher, B. A. and Thompson, R., Cambridge Univ. Press, Cambridge, UK, 199-230, doi:10.1017/CBO9780511535635.009, 1999

Tauxe, L.: Paleomagnetic principles and practice, Kluwer Academic Publisher, Dordrecht, the Netherlands, 301 pp., 1998.

Tong, Y., Zheng, S., and Qiu, Z.: Cenozoic mammal ages of China, Verterbrata Palasiatica, 33, 290-314, 1995 (in Chinese with English abstract).

Tong, Y. S., Li, Q., and Wang, Y. Q.: A brief introduction to recent advance in the Paleogene studies, J. Stratigr., 29, 109-133, 2005 (in Chinese with English abstract).

Tong, Y. S., Li, Q., and Wang, Y. Q.: An introduction to recent advance in the study of the continental Early Paleogene stages in China, J. Stratigr., 37, 428-440, 2013 (in Chinese with English abstract).

Verwey, E. J. W: Electronic conduction of magnetite $\left(\mathrm{Fe}_{3} \mathrm{O}_{4}\right)$ and its transition point at low temperatures, Nature, 144, 327-328, doi:10.1038/144327b0, 1939

Wang, B.: The Chinese Oligocene: A preliminary review of mammalian localities and local faunas, in: Eocene-Oligocene Climatic and Biotic Evolution, edited by: Prothero, D. R., and Berggren, W. A., Princeton University Press, Princeton, 529547, 1992 (in Chinese with English abstract).
Wang, B.: Problems and recent advances in the division of the continental Oligocene, Verterbrata Palasiatica, 21, 81-90, 1997 (in Chinese with English summary).

Wang, D., Lu, S., Han, S., Sun, X., and Quan, C.: Eocene prevalence of monsoon-like climate over eastern China reflected by hydrological dynamics, J. Asian Earth Sci., 62, 776-787, 2013.

Wang, J. D., Li, H. M., Zhu, Z. Y., Seguin, M. K., Yang, J. F., and Zhang, G. M.: Magnetostratigraphy of Tertiary rocks from Maoming Basin, Guangdong Province, China, Chinese J. Geochem., 13, 165-175, 1994.

Wang, Y. Y., Zhang, Z. H., and Jin, J. H.: Discovery of Eocene fossil mammal from Maoming Basin, Guangdong, Acta Scientiarum Naturalium Universitatis Sunyatseni, 46, 131-133, 2007 (in Chinese with English abstract).

Westerhold, T., Röhl, U., Pälike, H., Wilkens, R., Wilson, P. A., and Acton, G.: Orbitally tuned timescale and astronomical forcing in the middle Eocene to early Oligocene, Clim. Past, 10, 955-973, doi:10.5194/cp-10-955-2014, 2014.

Xiao, G. Q., Abels, H. A., Yao, Z. Q., Dupont-Nivet, G., and Hilgen, F. J.: Asian aridification linked to the first step of the EoceneOligocene climate Transition (EOT) in obliquity-dominated terrestrial records (Xining Basin, China), Clim. Past, 6, 501-513, doi:10.5194/cp-6-501-2010, 2010.

Yeh, H. K.: A new crocodile from Maoming, Kwangtung, Vertebrata Palasiatica, 2, 237-242, 1958 (in Chinese with English abstract).

Yu, J. F. and Wu, Z. J.: Spore-pollen assemblage of Mao 5 well of Maoming Basin, Guangdong and its geological age, J. Stratigr., 7, 112-118, 1983 (in Chinese).

Zachos, J. C., Pagani, M., Sloan, L., Thomas, E., and Billups, K.: Trends, rhythms, and aberrations in global climate $65 \mathrm{Ma}$ to present, Science, 292, 686-693, 2001.

Zanazzi, A., Kohn, M. J., MacFadden, B. J., and Terry, D. O. Jr.: Large temperature drop across the Eocene-Oligocene transition in central North America, Nature, 445, 639-642, 2007.

Zijderveld, J. D. A.: A. C. demagnetization of rocks: analysis of results, in: Methods in Palaeomagnetism, edited by: Collinson, D. W., Creer, K. M., and Runcorn, S. K., Elsevier, Amsterdam, 254-286, 1967.

Zong, G.: Cenozoic Mammals and Environment of Hengduan Mountains Region, China Ocean Press, Beijing, 279, 1996 (in Chinese with English abstract). 